\title{
Catalytic Mechanism of Nogalamycin Monoxygenase: How Does Nature Synthesize Antibiotics without a Metal Cofactor?
}

\section{DOI:}

10.1021/acs.jpcb.8b09648

\section{Document Version}

Accepted author manuscript

Link to publication record in Manchester Research Explorer

Citation for published version (APA):

Cantú Reinhard, F. G., Dubois, J. L., \& De Visser, S. P. (2018). Catalytic Mechanism of Nogalamycin Monoxygenase: How Does Nature Synthesize Antibiotics without a Metal Cofactor? The Journal of Physical Chemistry B. https://doi.org/10.1021/acs.jpcb.8b09648

\section{Published in:}

The Journal of Physical Chemistry B

\section{Citing this paper}

Please note that where the full-text provided on Manchester Research Explorer is the Author Accepted Manuscript or Proof version this may differ from the final Published version. If citing, it is advised that you check and use the publisher's definitive version.

\section{General rights}

Copyright and moral rights for the publications made accessible in the Research Explorer are retained by the authors and/or other copyright owners and it is a condition of accessing publications that users recognise and abide by the legal requirements associated with these rights.

\section{Takedown policy}

If you believe that this document breaches copyright please refer to the University of Manchester's Takedown Procedures [http://man.ac.uk/04Y6Bo] or contact uml.scholarlycommunications@manchester.ac.uk providing relevant details, so we can investigate your claim.

\section{OPEN ACCESS}




\title{
Catalytic Mechanism of Nogalamycin Monoxygenase: How Does Nature Synthesize Antibiotics Without a Metal Cofactor?
}

\author{
Fabián G. Cantú Reinhard, ${ }^{\ddagger}$ Jennifer L. DuBois ${ }^{\dagger}$ and Sam P. de Visser*,‡ \\ ${ }^{\ddagger}$ Manchester Institute of Biotechnology and School of Chemical Engineering and Analytical Science, The University of \\ Manchester, 131 Princess Street, Manchester M1 7DN, United Kingdom \\ ${ }^{\dagger}$ Department of Chemistry and Biochemistry, Montana State University, Bozeman, Montana 59715-3400, USA.
}

ABSTRACT: Nogalamycin monoxygenase (NMO) is a member of a family of enzymes that catalyze a key step in the biosynthesis of tetracycline antibiotics, used to treat, e.g., breast cancer in humans, using molecular oxygen for substrate oxidation but without an apparent cofactor. As most monoxygenases and dioxygenases contain a transition metal center $(\mathrm{Fe} / \mathrm{Cu})$ or flavin, this begs the question how $\mathrm{NMO}$ catalyzes this unusual oxygen atom transfer reaction from molecular oxygen to substrate directly. We performed a detailed computational study on the mechanism and catalytic cycle of NMO using density functional theory and quantum mechanics/molecular mechanics (QM/MM) on the full protein. We considered the substrate in various protonation states and its reaction with oxidant $\mathrm{O}_{2}$ as well as $\mathrm{O}_{2}^{-\bullet}$ through either electron transfer, proton transfer or hydrogen atom transfer. The lowest energy pathway for the models presented here is a reaction of the neutral substrate with a superoxo anion radical $\left(\mathrm{O}_{2}^{-{ }^{-0}}\right)$. In the absence of available free superoxo anions, however, the alternative neutral pathway between ${ }^{3} \mathrm{O}_{2}$ and substrate may be accessible at room temperature although the barrier is higher in energy by about $20 \mathrm{kcal} \mathrm{mol}^{-1}$ and therefore the reaction will be much slower. In contrast to previous experimental findings for both the enzymatic and uncatalyzed reactions, the mechanisms with the substrate in its deprotonated state were found to be high in energy, therefore mechanistic suggestions are proposed. A thermodynamic analysis shows that the substrate has a very weak $\mathrm{C}-\mathrm{H}$ bond that can be activated by a weak oxidant and hence a metal cofactor may not be needed for oxidizing this particular substrate. Finally, site-directed mutations were studied where active site Asn residues were replaced and highlight the function of these residues in guiding oxygen to the $\mathrm{C}^{12}$-position of the substrate. Overall, NMO shows a versatile reactivity pattern, where substrate can be activated by several low-energy pathways with oxidant and substrate in various oxidation and protonation states.

\section{Introduction.}

Monoxygenases are widely distributed enzymes that utilize molecular oxygen and transfer one oxygen atom to a substrate, with the second oxygen atom typically leaving as a water molecule. Because of the triplet nature of molecular oxygen, its reactivity with organic substrates is usually poor. Most often monoxygenation reactions will take place with the aid of a cofactor, such as reduced flavin, copper, or iron. ${ }^{1-6}$ For example, the cytochromes P450 are monoxygenases that are active in all forms of life, including the human body, where they operate mainly in the liver for the detoxification of xenobiotics and the biosynthesis of hormones, such as estrogen. ${ }^{7-13}$ The P450s undergo a catalytic cycle that is initiated with substrate binding and the reduction of the iron(III) center to enable dioxygen binding. A further reduction and two protonation steps then gives a high-valent iron(IV)-oxo heme cation radical active species that reacts with substrates through oxygen atom transfer. ${ }^{14-19}$

Interestingly, in Nature several mono- and dioxygenase families operate without the inclusion of a cofactor. The recently discovered, 1-H-3-hydroxy-4-oxoquinaldine 2,4dioxygenase (HOD) from Arthrobacter nitroguajacolicus Rübla, reacts as a ring-cleaving intradiol dioxygenase without the aid of metal or organic cofactors. ${ }^{20-23}$ In a combined kinetics and computational study, details of the catalytic cycle of HOD were established and it was confirmed that $\mathrm{O}_{2}$ reacts directly with substrate. ${ }^{24,25}$ 
(a)

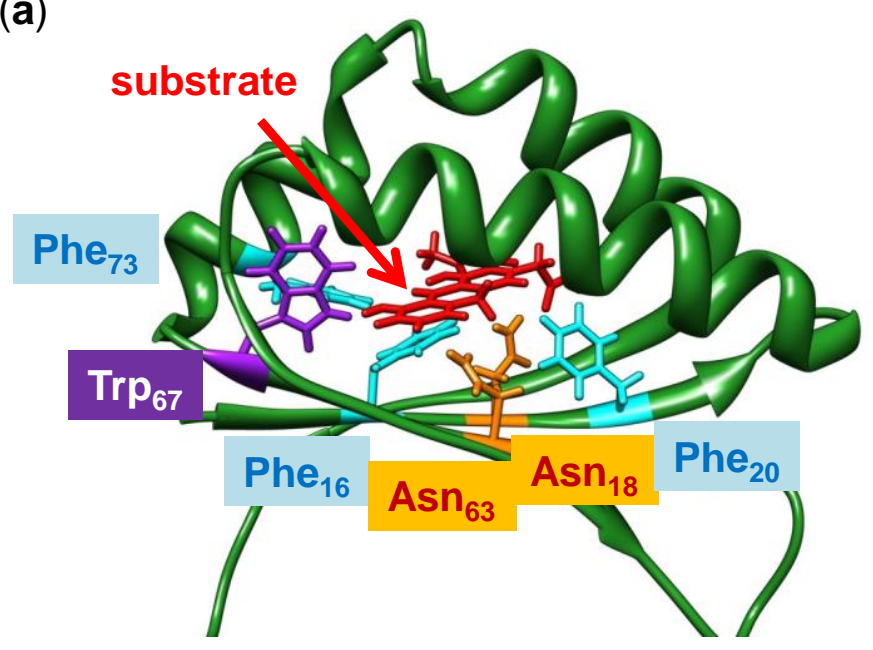

(b)

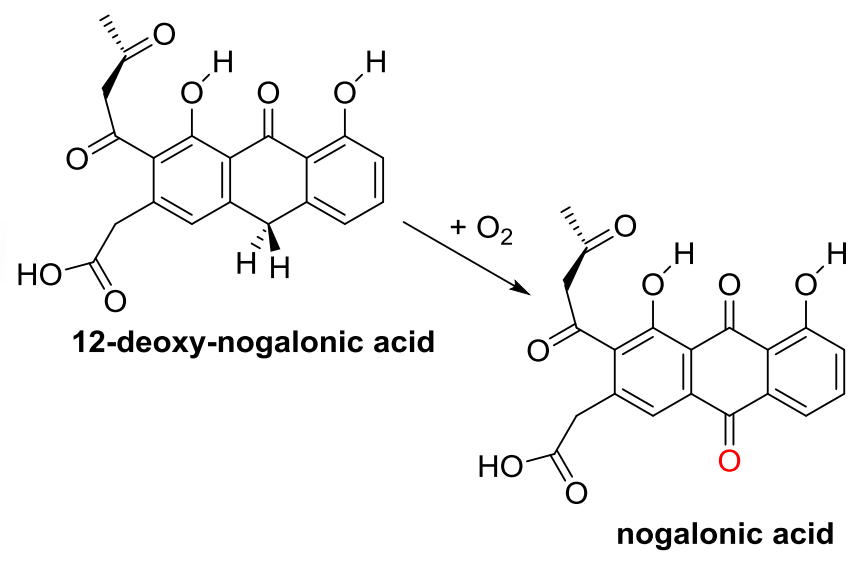

Figure 1. (a) Crystal structure (PDB ID: 3KNG) of NMO, encoded by the gene SnoaA, with substrate (12-deoxy-nogalonic acid) modeled in the active site pocket in the place of a molecule of bound crystallization solvent. (b) Reaction catalyzed by NMO.

In particular, it was shown that the aromatic substrate in a reaction with ${ }^{3} \mathrm{O}_{2}$ formed an arene-peroxo intermediate and through a spin-crossing from the triplet to the singlet spin state formed $\mathrm{N}$-acetyl-anthranilate and $\mathrm{CO}$ products. A more recent computational study on active site models; however, found the triplet-singlet crossing point prior to the $\mathrm{C}-\mathrm{O}$ bond formation transition state. ${ }^{26}$ As such, the activity and mechanism of cofactorless dioxygenases remains controversial and warrants further studies.

Structurally and evolutionarily distinct families of cofactorindependent monoxygenases are also known. The antibiotic biosynthesis monoxygenases (ABMs) are a large family of enzymes that catalyze a step in the biosynthetic pathways of several structurally distinct tetracycline antibiotics, including tetracenomycin, daunomycin, actonorhodin and nogalomycin. ${ }^{27-31}$ These molecules have widespread clinical use as antibiotics, anti-cancer agents, and anti-psoriasis drugs. The monoxygenase acts as a socalled decorating enzyme in conjunction with polyketide synthetases, inserting an $\mathrm{O}$-atom into the growing tetracycline scaffold. The ABM substrate, generally, needs to be activated prior to its reactivity, which suggests that they, like the substrate of HOD, facilitate the initial steps of their reactions with $\mathrm{O}_{2}$. The enzyme environment serves both to direct these reactions toward specific products and to accelerate their rates by several thousand-fold, relative to the uncatalyzed processes.

Nogalamycin monoxygenase (NMO) is an antibiotic biosynthesis monoxygenase from Staphylococcus nogalater that catalyzes the conversion of 12-deoxy-nogalonic acid to nogalonic acid (Figure 1). ${ }^{32,33}$ A $1.9 \AA$ resolution crystal structure has been measured for the enzyme with a molecule of ethylene glycol bound, which has been replaced by a model of the native substrate in the left-hand-side of
Figure 1. ${ }^{34-37}$ The substrate pocket is lined with aromatic amino acid residues, e.g., Phe ${ }_{16}, \mathrm{Phe}_{20}, \mathrm{Phe}_{73}$ and $\mathrm{Trp}_{67}$, which may have functions related to either $\pi$-stacking with the substrate or electron transfer. In addition, a number of polar residues potentially involved in hydrogen bonding interactions with substrate are located in the substrate binding pocket and the most prominent ones are $\mathrm{Asn}_{18}$ and Asn $_{63}$.

Clearly, there is an urgent need for a detailed computational study on the mechanism of substrate oxidation by NMO enzymes and a detailed comparison with HOD. In this paper, we present recent results using quantum mechanics/molecular mechanics ( $Q M / M M)$ on the reactivity of $\mathrm{O}_{2}$ inside the NMO complex, where we investigated several oxidation and protonation states of dioxygen and substrate 12-deoxy-nogalonic acid.

\section{Methods.}

The QM/MM model of NMO was set up using previously developed methods and procedures. ${ }^{38-40}$ We initially did exploratory density functional theory (DFT) calculations on small model complexes containing substrate and dioxygen. However, later we also employed QM/MM on the full enzyme including models with active site amino acid residues in the QM region. We will focus in the main text on the QM/MM results; however, we will show some of the small model results in the discussion. Full details of all calculations can be found in the Supporting Information.

Model set-up. A QM/MM model was set up starting from the crystal structure coordinates with protein databank code $3 \mathrm{KNG} .^{34}$ Following the experimental studies of Ref 33, we used dithranol as a substrate of NMO. Dithranol 
was manually created and geometry optimized in Gaussian $09^{41}$ at the B3LYP/6-31G* level of theory with polarized continuum model included. ${ }^{42-44}$ CHARMM parameters for dithranol were generated with SwissParam. ${ }^{45}$ Subsequently, the substrate was docked into the protein structure at a low-energy conformation as determined in SwissDock. ${ }^{46,47}$ Thereafter, dioxygen was placed in a position near the active site Asn residues. A standard procedure was followed for the subsequent set-up of the system, as described in more detail elsewhere ${ }^{38-40,48-51}$ and briefly summarized here.

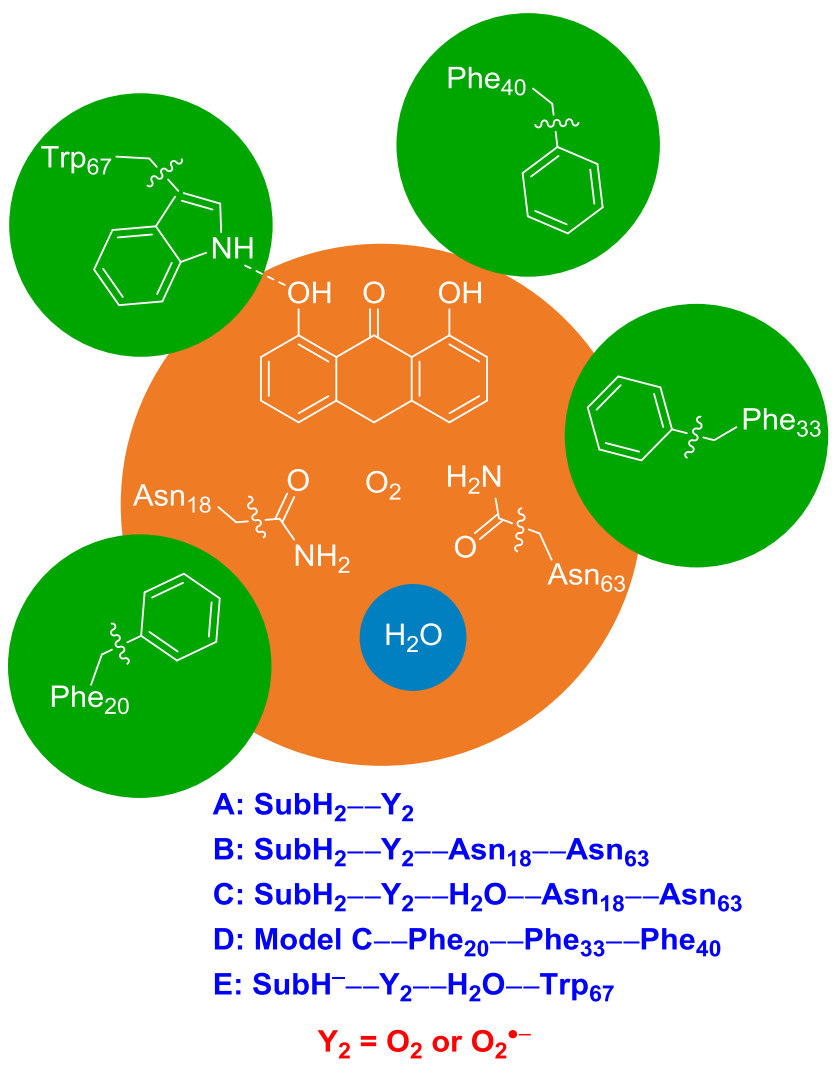

Figure 2. $Q M$ regions selected for the $Q M / M M$ calculations with either $\mathrm{Y}_{2}=\mathrm{O}_{2}$ or $\mathrm{O}_{2}{ }^{-*}$ as oxidant. Wiggly lines represent the border between the $Q M$ and $M M$ regions and dithranol is abbreviated as $\mathrm{SubH}_{2}\left(\mathrm{SubH}^{-}\right.$if deprotonated) in the model descriptions.

The enzyme model was set up using procedures proposed by Thiel et al. ${ }^{52,53}$ The substrate bound enzyme structure with dioxygen bound was protonated to $\mathrm{pH} 7$ with the PROPKA method using the PDB2PQR web service, ${ }^{54}$ whereby all Glu and Asp side chains were deprotonated and all Arg and Lys side chains protonated. All histidine residues were taken in their singly protonated form except $\mathrm{His}_{49}$ that was doubly protonated. Thereafter, an iterative solvation procedure was implemented through 20 cycles of solvation with a water sphere of $35 \AA$ of radius (Supporting Information Figure S1). The fully solvated system consisted of 21,441 atoms, including 6,658 TIP3P water molecules. The system was neutralized with $10 \mathrm{Mg}^{2+}$ and $18 \mathrm{Cl}^{-}$ions randomly spaced in the solvent layer surrounding the protein. The $\mathrm{Mg}^{2+}$ ions were described with the forcefield developed by Dalmas et al, while chloride with the Charmm27 forcefield. ${ }^{55,56}$

Subsequently, the model was heated and equilibrated to room temperature using the Charmm 27 forcefield with the protein backbone atoms fixed. ${ }^{55,56}$ Finally, an 1000 ps molecular dynamics (MD) simulation was carried out in Charmm with an unconstrained protein. As follows from an overlay of the start and final structures of this MD run (Supporting Information Figures S11 and S12) most residues are located in virtually the same position and little structural changes to the protein are seen. We maintained a fixed water molecule close to the substrate for further studies. Snapshots were obtained after 450, 500, 550 and 600 ps, designated $\mathrm{Sn}_{450}, \mathrm{Sn}_{500}, \mathrm{Sn}_{550}$ and $\mathrm{Sn}_{600}$, respectively. The full mechanistic study of the reaction mechanism was performed at minimally one snapshot per case, while the rate-determining step was investigated for multiple snapshot structures.

In addition to studies of the wildtype (WT) structure, we also investigated a double mutant (Asn18Ala/Asn63Ala), whereby Asn was manually replaced by Ala and the molecular dynamics simulations were repeated. Snapshots were again taken at $450,500,550$ and 600 ps.

QM/MM Calculations. As the border between $Q M$ and $M M$ region and the size of the $Q M$ model can affect the structure and energetics of reaction mechanisms, we tested several $Q M$ regions as shown in Figure 2. The smallest $Q M$ model contained only substrate and $\mathrm{O}_{2}(\mathrm{QM}$ region A) and was used as a DFT-only model. In addition, calculations were done where $Q M$ region $A$ was expanded with two Asn side chains (QM region $B$ ). Then a larger $Q M$ region tested contained the full substrate, $\mathrm{O}_{2}$, one crystallographically placed water molecule and both Asn side chains (QM region $C$ ). In another set of calculations, we added three active site Phe side chains to $Q M$ region $C$ to give $Q M$ region $D$. Finally, a potential role of close lying hydrogen-bonding $\operatorname{Trp}_{67}$ was explored in the deprotonated substrate pathway in $Q M$ region $E$. In the mutant structures, the two proximal asparagine functional groups were replaced by alanine side chains. The border regions between the $Q M$ and $M M$ regions of the asparagine (alanine in the mutants) residues were defined with hydrogen link-atoms and the interaction of the $Q M$ and $M M$ systems was treated by electrostatic embedding. ${ }^{57-59}$ 
<smiles></smiles>

$+\mathrm{O}_{2} \uparrow$ HAT

pathway (i) 19.2 / 14.4

$+\mathrm{OOH}^{\circ}$
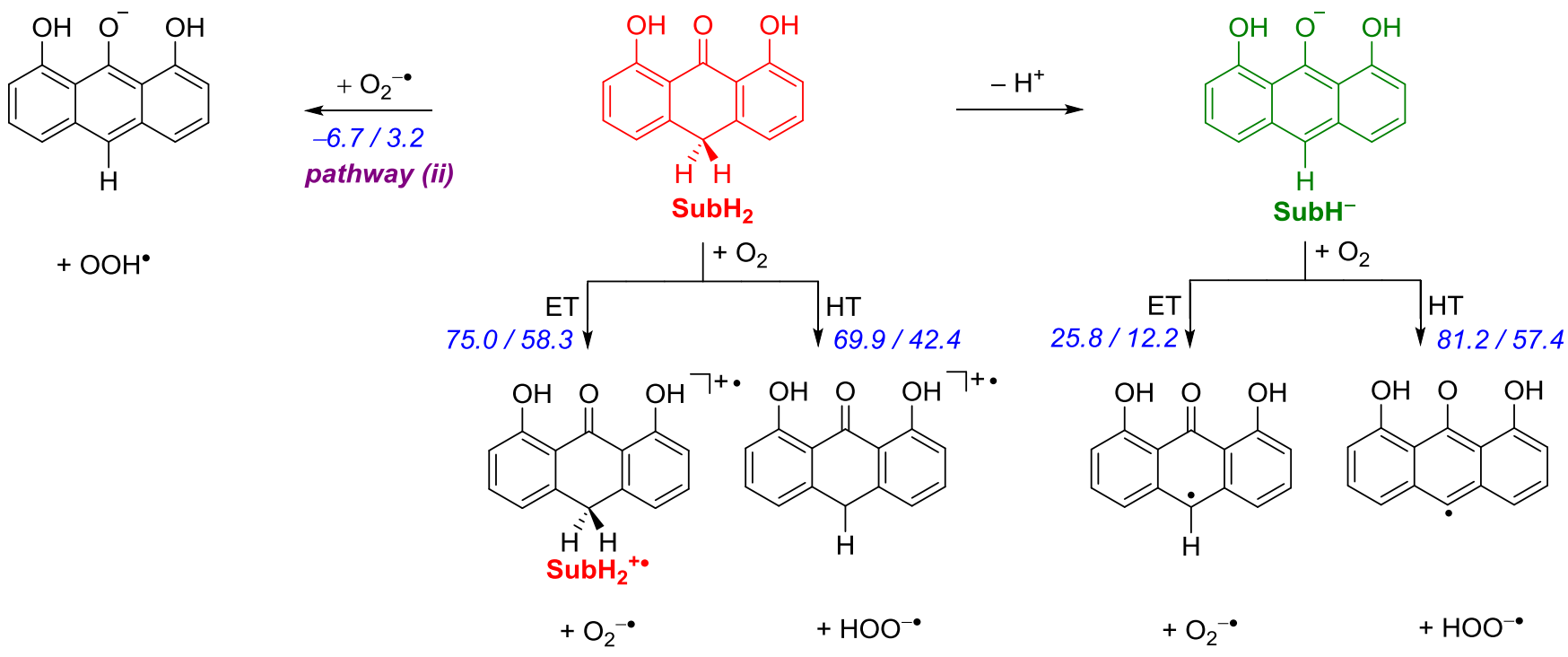<smiles>[O-][18O][O-]</smiles>

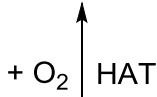

pathway (iii) 25.2 / 21.8

Figure 3. Possible pathways for proton, electron, hydrogen atom and hydride transfer of dithranol in NMO as calculated with gas-phase model structure $A$. Reaction free energies $\left(\Delta G_{\text {reaction }}\right.$ in $\left.\mathrm{kcal} \mathrm{mol}^{-1}\right)$ calculated using DFT models in water at UB3LYP level of theory in Gaussian at 298K from the difference between isolated product and reactant structures. The two sets of data were obtained with a $6-31 G^{*}$ and $6-311++G^{* *}$ basis set, respectively.

In addition to the presented models, a larger neutral system encompassing all relevant amino acids in the QM region $\mathrm{F}\left(\mathrm{Asn}_{18}, \mathrm{Asn}_{63}, \mathrm{Phe}_{20}, \mathrm{Phe}_{33}\right.$, $\mathrm{Phe}_{40}$, and $\left.\mathrm{Trp}_{67}\right)$ was also optimized as a reactant complex, although no mechanistic investigations were performed at that size. The $Q M$ section was calculated with Turbomole ${ }^{60}$ at the unrestricted B3LYP ${ }^{42,43}$ level of theory, whilst the MM region was calculated with the Charmm27 forcefield as implemented in DL-Poly. ${ }^{55,56,61,62}$ The QM and MM software packages were interfaced by Chemshell. ${ }^{63}$ We did full geometry optimization of reactants, intermediates, products and transition states at the B3LYP/BS1 level of theory $(\mathrm{BS} 1=$ SVP basis set). ${ }^{42,43,64}$ To establish the nature of the transition states and make sure they indeed connect to reactants and products, we ran extensive geometry scans whereby one degree of freedom was fixed (the $\mathrm{O}-\mathrm{H}$ or $\mathrm{C}-\mathrm{O}$ distance) while all other degrees of freedom were minimized. The energetics of the optimized structures was improved through single point calculations at the B3LYP/BS2 with BS2 = def-TZV(P) basis set. For one set of calculations, we also did full geometry optimizations using B3LYP/BS2, but the results were similar to those obtained with the smaller basis set. See Supporting Information.

Results.

Protonation state of oxidant and substrate. Currently, the experimental studies are unclear about the oxidation and protonation states of substrate and oxidant in NMO enzymes. Therefore, we did a series of small molecule test calculations on the proton and electron transfer capabilities of the substrate and oxidant in various oxidations states. These studies highlight the most likely scenarios that were subsequently tested with $\mathrm{QM} / \mathrm{MM}$ and identified with pathways (i), (ii) and (iii) in Figure 3.

Our initial studies were focused on establishing computationally the most likely protonation and oxidation states of substrate (dithranol) and oxidant. In addition, reactions were considered for substrate with $\mathrm{O}_{2}$ via either electron transfer (ET), hydrogen atom transfer (HAT) or hydride transfer (HT) as described in Scheme S1. Figure 3 summarizes all possible reaction pathways for dithranol in a reac- 
tion with molecular oxygen, protons, electrons and/or hydride anions. These studies should give insight into the electronic configuration of the dioxygen-bound structure of NMO and the likely protonation state of the substrate. Focusing first on the neutral substrate $\left(\mathrm{SubH}_{2}\right.$, highlighted in red in Figure 3), DFT calculations on small model complexes calculated at the B3LYP/6-31G* and B3LYP/6$311++G^{* *}$ level of theory with a polarized continuum model mimicking water were performed (Tables S1 - S4, Supporting Information). In general the two sets of calculations give the same trends and lead to the same conclusions. We find a reaction energy for the electron transfer reaction for reaction 1 of $\Delta G=75.0$ and $58.3 \mathrm{kcal} \mathrm{mol}^{-1}$.

${ }^{3} \mathrm{O}_{2}+\mathrm{SubH}_{2} \rightarrow{ }^{2} \mathrm{O}_{2}^{-\bullet}+\mathrm{SubH}_{2}^{+\bullet}$

Indeed, a large active site model complex that contains the substrate, $\mathrm{O}_{2}$ and several protein residues calculated with DFT gives an electronic configuration that represents a neutral $\mathrm{O}_{2}$ molecule nearby $\mathrm{SubH}_{2}$ rather than a charge transfer complex of superoxo with substrate cation radical (Table S7, Supporting Information). To make sure that the results were not affected by the choice of the density functional method, we employed $\operatorname{CCSD}(T)$ single points with solvent model (water) included on the DFT optimized geometries. At CCSD(T) level of theory an electronic configuration similar to the one found with B3LYP/BS2 is obtained with a ${ }^{3} \mathrm{O}_{2}$ nearby a neutral substrate.

Finally, an orbital swap was attempted at the DFT and $\operatorname{CCSD}(T)$ level of theory, whereby we generated an electronic configuration representing the charge-transfer state. During the SCF convergence of all of these calculations; however, they reverted back to the neutral state for the interaction of ${ }^{3} \mathrm{O}_{2}$ with a neutral SubH molecule. Consequently, the calculations predict the neutral state to be the ground state for the $\left[\mathrm{O}_{2}--\mathrm{SubH}_{2}\right]$ complex. Therefore, based on gas-phase DFT models we do not expect electron transfer to happen between a neutral substrate and $\mathrm{O}_{2}$ spontaneously. This observation is similar to what was recently found for the cofactor independent dioxygenase $H O D$, where also no electron transfer took place in the neutral reactant complex. ${ }^{24,25}$ However, our results conflict experimental studies ${ }^{35-37}$ on $\mathrm{NMO}$ enzymes that proposed an electron transfer from substrate to $\mathrm{O}_{2}$ upon its entrance into the substrate binding pocket. To find out whether the contradiction is due to the choice of the model, we continued our studies with a full protein model (see below). In addition to the electron transfer we considered direct hydride abstraction from dithranol by $\mathrm{O}_{2}$, but large endothermicities of $69.9 / 42.4 \mathrm{kcal} \mathrm{mol}^{-1}$ were found in vacuo with the two different basis sets; hence this process is unfeasible. On the other hand, a direct hydrogen atom ab- straction (HAT) has a reaction energy of $\Delta G=19.2 \mathrm{kcal}$ $\mathrm{mol}^{-1}$, which drops to $14.4 \mathrm{kcal} \mathrm{mol}^{-1}$ when a $6-311++\mathrm{G}^{* *}$ basis set is used and, therefore, may be accessible in the protein. Especially, since the experimental reaction rate ${ }^{33}$ of $k=0.0028 \mathrm{~min}^{-1}$ would correspond to a free energy of activation of $\Delta \mathrm{G}^{\ddagger}=22.2 \mathrm{kcal} \mathrm{mol}^{-1}$ at $298 \mathrm{~K}$.

Subsequently, we considered a neutral substrate in reaction with superoxo radical anion $\left({ }^{2} \mathrm{O}_{2}^{-\bullet}\right)$. Much lower reaction energies are found in a reaction of neutral dithranol with $\mathrm{O}_{2}{ }^{-\bullet}$ instead, where an exergonic reaction for proton transfer of $-6.7 \mathrm{kcal} \mathrm{mol}^{-1}$ is found. At the same level of theory we calculate an electron affinity (EA as defined in Eq 2) of ${ }^{3} \mathrm{O}_{2}$ of $12.8 \mathrm{kcal} \mathrm{mol}^{-1}$.

${ }^{3} \mathrm{O}_{2}+\mathrm{e}^{-} \rightarrow{ }^{2} \mathrm{O}_{2}^{-\cdot}$

Therefore, an ionizable side chain such as the imidazolium group of an active site tryptophan could hypothetically relay electrons from a reduction partner to ${ }^{3} \mathrm{O}_{2}$ in the active site and generate superoxo anion radical (Figure 1). Surprisingly, no reductase partner is known for the reaction in vivo, in which the enzyme, $\mathrm{O}_{2}$, and the organic substrate appear to be sufficient for yielding the oxygenated product and water. As such, we decided to continue the work with $Q M / M M$ and consider the effect of the protein on the reaction mechanism.

Next, we considered the possibility of dithranol being deprotonated prior to dioxygen binding (right-hand-side of Figure 3). Experimental work above the singleprotonation $\mathrm{p} K_{\mathrm{a}}$ of the enzyme-substrate complex (6.9) showed that oxygenation is the dominant process, whereas in acidic environments the reaction appeared to undergo a net one-electron/one-proton oxidation to yield a dimeric product. ${ }^{33}$ The latter is an unwanted side product in the biological context, as it is off the pathway leading ultimately to the antibiotic. As such, the reaction processes for electron transfer, hydrogen atom abstraction and hydride transfer were repeated using $\mathrm{SubH}^{-}$as the substrate (right-hand-side of Figure 3).

Electron transfer from deprotonated dithranol $\left(\mathrm{SubH}^{-}\right)$to ${ }^{3} \mathrm{O}_{2}$ has a much lower reaction energy than that of dithranol to ${ }^{3} \mathrm{O}_{2}\left(+25.8\right.$ versus $\left.75.0 \mathrm{kcal} \mathrm{mol}^{-1}\right)$, although the value drops to $12.2 \mathrm{kcal} \mathrm{mol}^{-1}$ with a $6-311++\mathrm{G}^{* *}$ basis set. Hence, the electron transfer is still considerably endothermic and will be difficult to achieve in the gas phase model. Furthermore, hydride transfer from deprotonated dithranol is also unlikely to take place as it has a very high reaction energy of well over $60 \mathrm{kcal} \mathrm{mol}^{-1}$. Alternatively, a hydrogen atom transfer from deprotonated substrate to $\mathrm{O}_{2}$ may occur to form the hydroperoxyl radical, although a relatively large endothermicity of $25.2 \mathrm{kcal} \mathrm{mol}^{-1}$ is required. 

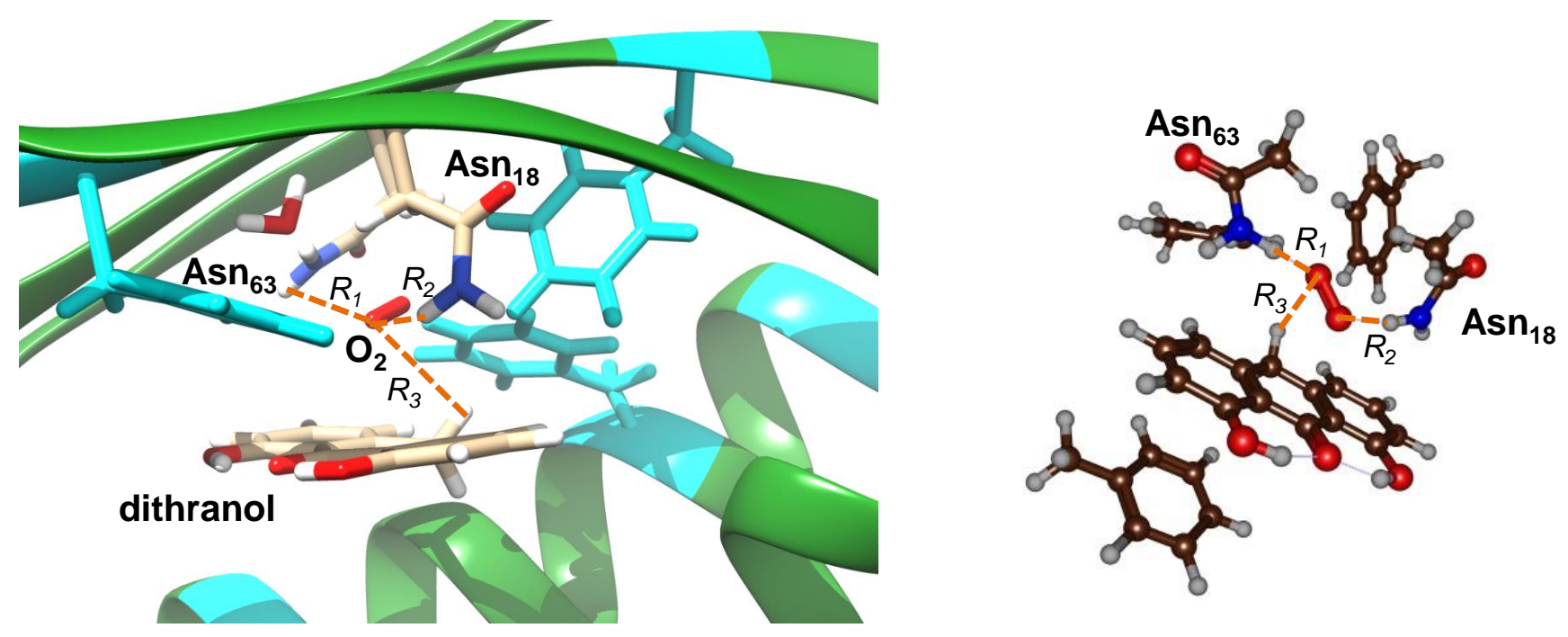

\begin{tabular}{|l|c|c|c|c|c|} 
& Charge & $\boldsymbol{R}_{1}$ & $\boldsymbol{R}_{2}$ & $\boldsymbol{R}_{3}$ & $\rho\left(\mathbf{O}_{2}\right)$ \\
\hline $\mathrm{Sn}_{450}$ & 0 & $2.70(2.65)$ & $2.39(2.69)$ & $2.83(2.96)$ & $2.0(2.0)$ \\
\hline $\mathrm{Sn}_{500}$ & 0 & $2.50(2.64)$ & $2.71(2.66)$ & $2.83(3.00)$ & $2.0(2.0)$ \\
\hline $\mathrm{Sn}_{550}$ & 0 & $2.65(2.64)$ & $2.57(2.74)$ & $2.78(2.89)$ & $2.0(2.0)$ \\
\hline $\mathrm{Sn}_{450}$ & -1 & $1.77(1.72)$ & $1.79(1.76)$ & $2.27(2.56)$ & $1.1(1.0)$ \\
\hline $\mathrm{Sn}_{500}$ & -1 & $1.79(1.69)$ & $1.86(1.79)$ & $1.83(2.48)$ & $1.0(1.0)$ \\
\hline $\mathrm{Sn}_{550}$ & -1 & $1.89(1.94)$ & $1.84(1.86)$ & $2.09(2.23)$ & $1.1(1.1)$ \\
\hline
\end{tabular}

Figure 4. QM/MM optimized geometries of the neutral and anionic reactant complexes ( ${ }^{3} \mathrm{Re}^{0}$ and ${ }^{2} \mathrm{Re}^{-}$) as obtained in Turbomole:Charmm at the B3LYP/BS1:Charmm27 level of theory. Bond lengths are defined in the Figure and displayed in angstroms. Dioxygen spin densities are in au. Values reported are for obtained geometries with $Q M$ region $B(D)$ for $Y_{2}=O_{2} / O_{2}^{-{ }^{-}}$with overall charge 0 or -1 , respectively.

The results in Figure 3, therefore, implicate that the most reactive gas phase form of dithranol is the protonated state, i.e. $\mathrm{SubH}_{2}$, and a hydrogen atom abstraction reaction can take place by either $\mathrm{O}_{2}$ or $\mathrm{O}_{2}^{-\bullet}$ via low-energy pathways. The availability of $\mathrm{O}_{2}^{-\bullet}$ in the protein will depend on the presence of a reduction partner that can deliver the needed electrons. We therefore undertook a full QM/MM investigation on the full protein with models containing either $\mathrm{O}_{2}$ or $\mathrm{O}_{2}^{-\bullet}$. However, for completeness, the hydrogen atom transfer process pathway of the deprotonated substrate was also investigated in full, whereby a Trp residue was included in the QM region because of its hydrogen bonding interaction with the $\mathrm{OH}$ group.

QM/MM studies on $\mathrm{O}_{2} / \mathrm{O}_{2}^{-\bullet}$ binding. First, a full $\mathrm{QM} / \mathrm{MM}$ calculation on the ternary dioxygen- and neutral dithranol-bound complex of NMO was performed. Figure 4 displays the QM/MM optimized geometry of the reactant complex $\left({ }^{3} \mathrm{Re}^{0}\right)$ in the overall triplet spin state. We specify the spin multiplicity in superscript before the label and the overall charge in superscript after the label. The pocket in between the $A s n_{18}$ and $A_{s n_{63}}$ amino acid residues fits molecular oxygen well, but during the solvation and dynamics set-up procedures also one water molecule entered. The substrate binding pocket contains three aromatic phenylalanine and one tryptophan residue, which may interact with the substrate.

In the reactant complex, all spin density is located on dioxygen and no spin density is seen on the dithranol substrate. Thus, the QM/MM model shows that in agreement with the small DFT gas phase model complexes and $\operatorname{CCSD}(T)$, the reactant complex corresponds to ${ }^{3} \mathrm{O}_{2}$ in the 
vicinity of dithranol $\left(\mathrm{SubH}_{2}\right)$ and no electron transfer between the two groups has taken place. Dioxygen and water form hydrogen bonding interactions with the Asn side chains.

Optimized geometries show little differences between the various snapshots. Figure 4 displays the interactions between $\mathrm{O}_{2}$ and the nearest protons of $A_{s n_{63}}$ (distance $\mathrm{R}_{1}$ ) and $A_{s n_{18}}$ (distance $R_{2}$ ) as well as the distance between $\mathrm{O}_{2}$ and one of the hydrogen atoms bound to carbon $\mathrm{C}^{12}$ (distance $R_{3}$ ). Obviously, inclusion of the Asn side chains into the $Q M$ region affects the hydrogen bonding interactions between these groups but in all cases the interaction remains weak and $R_{1}$ and $R_{2}$ are well over $2.5 \AA$ in ${ }^{3} \operatorname{Re}^{0}$. A similar result was obtained by using the larger $Q M$ region (model F) whereby only unpaired spin density on the oxygen molecule was found. Therefore, the different snapshots give some flexibility in the position of $\mathrm{O}_{2} / \mathrm{O}_{2}{ }^{-}$binding, but the electronic configuration varies little between the various snapshots. Thus, both DFT model complexes (Figure 3) as well as QM/MM on the full protein show that a complex of $\mathrm{SubH}_{2}$ with ${ }^{3} \mathrm{O}_{2}$ does not lead to electron transfer. Our work contrasts experimental suggestions that upon $\mathrm{O}_{2}$ binding a spontaneous electron transfer takes place. $^{32,33}$ In recent $Q M / M M$ calculations on the firefly luciferin reaction it was found that $\mathrm{O}_{2}$ upon binding nearby a luciferin-adenylate led to spontaneous electron transfer. ${ }^{65}$ Clearly, the ionization potential of $\mathrm{SubH}_{2}$ used here is considerably different from luciferin-adenylate and consequently no electron transfer is possible. We, therefore, considered different protonation states of the substrate as well as oxidation states.

Next, we did a series of QM/MM calculations with the $Q M$ region with overall charge -1 and an overall doublet spin state: ${ }^{2} \mathrm{Re}^{-}$. These systems have the charge and spin fully located on the $\mathrm{O}_{2}$ moiety and hence can be characterized as $\left[\mathrm{SubH}_{2}-\mathrm{-O}_{2}^{-{ }^{-*}}\right.$ ] complexes. Bond lengths $\mathrm{R}_{1}, \mathrm{R}_{2}$ and $R_{3}$ are considerably shorter with superoxo bound then with molecular oxygen by at least $0.5 \AA$ and in some cases even $1 \AA$. Therefore, superoxo will be able to approach the substrate more closely and is more likely to react via hydrogen atom abstraction. Clearly, the negatively charged $\mathrm{O}_{2}^{-\bullet}$ is held more tightly in position by the Asn side chain groups that are set up for selective hydrogen atom abstraction.

Pathway (i): Reaction of $\mathrm{SubH}_{2}$ with ${ }^{3} \mathrm{O}_{2}$. Subsequently, we investigated the reaction mechanism of oxygen atom transfer to substrate starting from the ${ }^{3} \mathrm{Re}^{0}$ and ${ }^{2} \mathrm{Re}^{-} \mathrm{com}-$ plexes, whereby approach of ${ }^{3} \mathrm{O}_{2}$ or ${ }^{2} \mathrm{O}_{2} \cdot \cdot$ initiates the reaction. These represent the reactions expected to occur below $\mathrm{pH} 6.9$, i.e. the $\mathrm{p} K_{\mathrm{a}}$ of the $\mathrm{NMO}$-substrate complex. $^{32,33}$ The mechanism for this reaction was not studied experimentally; however, it was shown that the monoxygenation product (dithranone) was a minor product; the major product was bisanthrone, the dimerized form of the neutral substrate radical.

Figure 5 displays the mechanism starting from ${ }^{3} \mathrm{Re}^{0}$ for oxygenation of dithranol as obtained with $Q M / M M$ using $Q M$ region $C$, which includes dithranol, oxidant, the two active site Asn groups and one water molecule. We calculated the full mechanism on the triplet and singlet spin states for snapshot $\mathrm{Sn}_{450}$, but did an additional set of calculations for the rate-determining step in snapshots $\mathrm{Sn}_{500}$ and $\mathrm{Sn}_{550}$.

We will first cover the results on the full mechanism as calculated with snapshot $\mathrm{Sn}_{450}$. The triplet spin state is the ground state and the lowest energy singlet spin state is higher in energy by $36.5 \mathrm{kcal} \mathrm{mol}^{-1}$ at B3LYP/BS2:Charmm level of theory (as calculated with $\mathrm{QM}$ region $\mathrm{C}$ and snapshot $\mathrm{Sn}_{450}$ ). At B3LYP/BSI:Charmm level of theory the triplet-singlet energy gap is much smaller, but the calculation had a large amount of spin contamination, which was not the case at B3LYP/BS2 level of theory (Supporting Information). Note, all other BS1 results had the required expectation value of $S^{2}$ in the calculation. In agreement with the predictions from gas phase DFT model complexes (Figure 3), the initial hydrogen atom abstraction from $\mathrm{SubH}_{2}$ by $\mathrm{O}_{2}$ is high in energy with barriers ${ }^{3} \mathrm{TS}_{\text {HAT,O }}$ and ${ }^{1} \mathrm{TS}_{\text {HAT,O }}$ of 27.9 and $31.6 \mathrm{kcal} \mathrm{mol}^{-1}$ in the triplet and singlet spin states $\left(\mathrm{Sn}_{450}\right)$, respectively. The same triplet/singlet spin state ordering is observed in the radical intermediates $\left.{ }^{1,3}\right|_{\mathrm{A}, 0}$, which represents an $\mathrm{OOH}$ radical nearby SubH ${ }^{\circ}$. In the next step the $\mathrm{OOH}$ radical attacks $\mathrm{SubH}^{\circ}$ and a covalent $\mathrm{C}-\mathrm{O}$ bond is formed to generate the $\mathrm{Sub}(\mathrm{H}) \mathrm{OOH}$ intermediate $\mathrm{I}_{\mathrm{B}, 0}$ via transition state $\mathrm{TS}_{\mathrm{CO}, 0}$. This step is high in energy on the triplet spin state surface and a spin-state crossing from the triplet to the singlet spin state will be required to form ${ }^{\prime} l_{B, O}$. Failure of the intermediate to undergo the spin-state crossing could yield the neutral substrate radical and $\mathrm{OOH}$ radical products, which diffuse from the active site and ultimately lead to bisanthrone as the major product. Alternatively, formation of ${ }^{1} \mathrm{I}_{B, 0}$ following the spin crossing is highly exothermic. In a final reaction step the hydroperoxo group abstracts the other hydrogen atom from carbon atom $\mathrm{C}^{12}$ and dissociates a water molecule from the complex via $\mathrm{TS}_{\mathrm{W}, 0}$ to form products $P_{0}$. The last step is highly exothermic and may be further stabilized by access of additional water molecules or other hydrogen bonding groups.

The reaction mechanism shown in Figure 5 starts with a high energy hydrogen atom abstraction barrier and leads to a stable radical intermediate. Only after the triplet radical intermediate is formed, a spin-state-crossing takes place to the singlet-spin state that relaxes to products. 


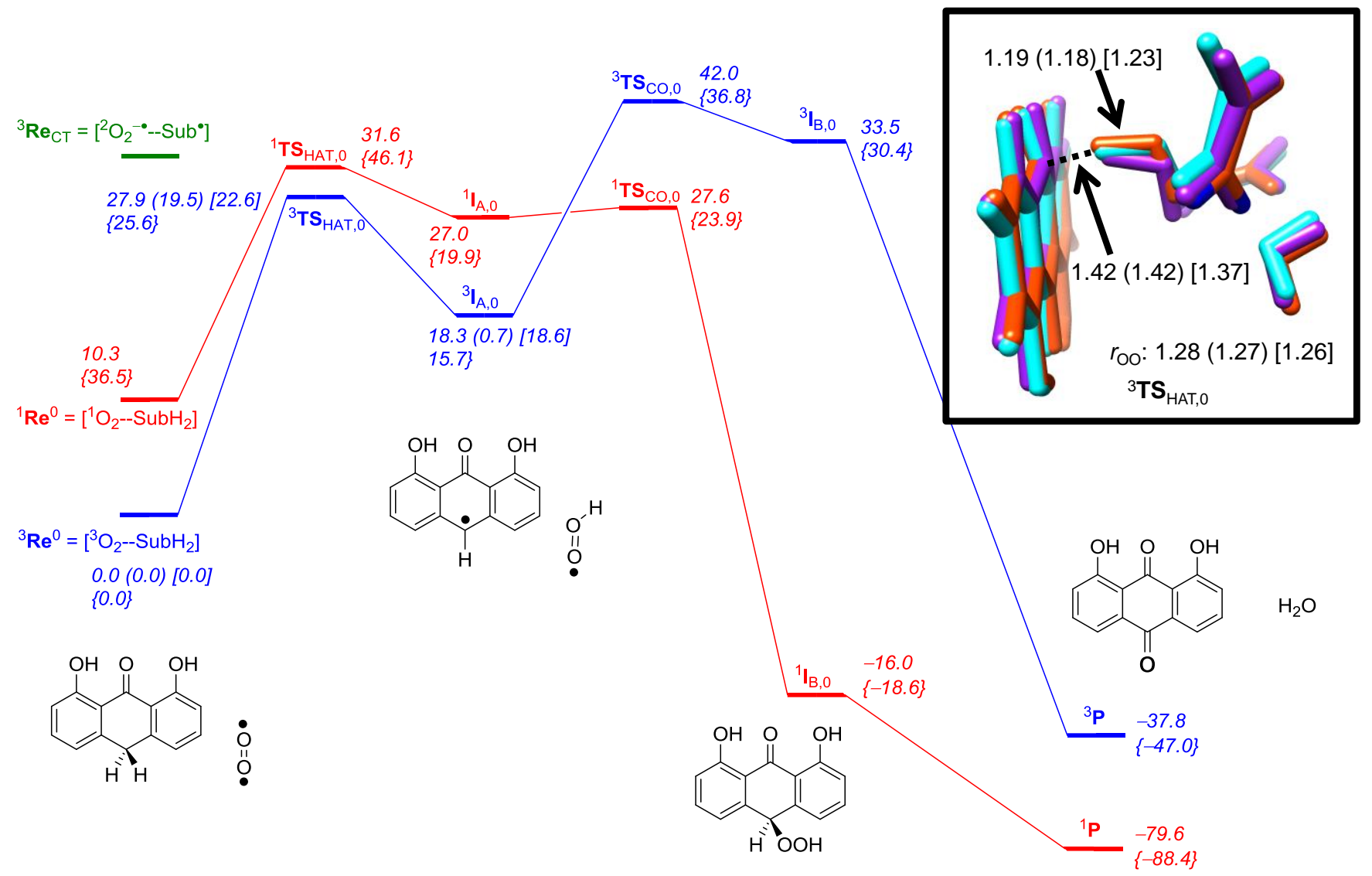

Figure 5. Potential energy landscape (with values in $\mathrm{kcal} \mathrm{mol}^{-1}$ ) for dithranol $\left(\mathrm{SubH}_{2}\right.$ ) activation by ${ }^{3} \mathrm{O}_{2}$ inside $\mathrm{NMO}$ as calculated with $Q M / M M$. Formation of the monoxygenase product is depicted. Energies obtained with $Q M / M M$ at the UB3LYP/BS1:Charmm27 level of theory with QM region C for snapshots $S_{450}\left(S_{500}\right)\left[\mathrm{Sn}_{550}\right.$ ]. Values in curly brackets obtained with basis set BS2. The inset gives an overlay of the optimized geometries of ${ }^{3} \mathrm{TS}_{\mathrm{HAT}, \mathrm{O}}$ for the three snapshots containing substrate, $\mathrm{O}_{2}$ and the side-chains of the two Asn residues with bond lengths in angstroms $\left(\mathrm{Sn}_{450}\right.$ in amber, $\mathrm{Sn}_{500}$ in light blue and $\mathrm{Sn}_{550}$ in purple).

However, prior to this spin-state crossing the radical can diffuse out of the substrate binding pocket and react with another radical to form bisanthrone products. Consequently, this mechanism is consistent with what was observed for the $\mathrm{NMO}$-catalyzed reaction at acidic $\mathrm{pH}$.

The hydrogen atom abstraction step was calculated for three snapshots $\left(\mathrm{Sn}_{450}, \mathrm{Sn}_{500}\right.$ and $\left.\mathrm{Sn}_{550}\right)$ at B3LYP/BS1:Charmm and for snapshot $\mathrm{Sn}_{450}$ also at the B3LYP/BS1:Charmm/ /B3LYP/BS2:Charmm level of theory. The two energy values for $\mathrm{Sn}_{450}$ are within a few kcal $\mathrm{mol}^{-1}$ from each other and therefore appear to have little effect on the mechanism and conclusions. Group spin densities and charges (Supporting Information) implicate all ${ }^{3} \mathrm{TS}_{\text {HAT }}$ barriers to represent hydrogen atom abstraction barriers with no excess charge on the substrate and a charge neutral $\mathrm{O}_{2}$ group.

An overlay of the three optimized geometries of the QM region of these ${ }^{3} \mathrm{TS}_{\mathrm{HAT}, \mathrm{O}}$ transition states are given in the inset of Figure 5. As can be seen, the transition states are late with long $\mathrm{C}-\mathrm{H}$ and short $\mathrm{O}-\mathrm{H}$ distances. The optimized geometries of the various snapshots give structures that are very much alike; however, the energies fluctuate strongly. In particular, $\mathrm{Sn}_{500}$ gives a hydrogen atom abstraction transition state of $19.5 \mathrm{kcal} \mathrm{mol}^{-1}$, whereas it is 27.9 and $22.6 \mathrm{kcal} \mathrm{mol}^{-1}$ for $\mathrm{Sn}_{450}$ and $\mathrm{Sn}_{550}$, respectively.

To test whether the size of the QM region has an effect on the reaction mechanism and rate constant of hydrogen atom abstraction, we ran additional $\mathrm{QM} / \mathrm{MM}$ calculations without the bridging water molecule in the $Q M$ region, QM region $B$. 


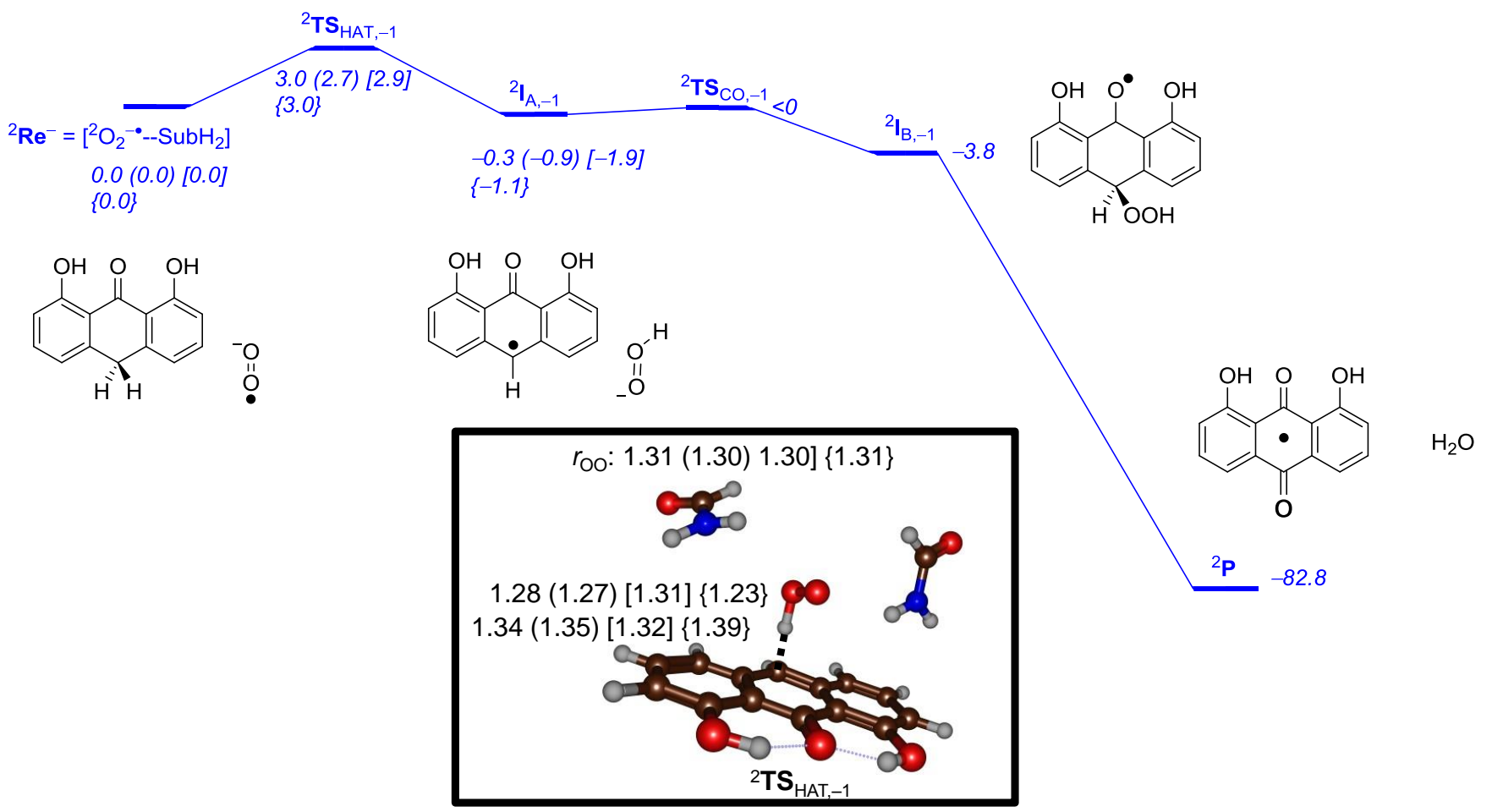

Figure 6. Potential energy landscape (with values in $\mathrm{kcal} \mathrm{mol}^{-1}$ ) for dithranol activation by ${ }^{2} \mathrm{O}_{2}{ }^{-\bullet}$ inside $\mathrm{NMO}$ as calculated with QM/MM. Energies obtained with QM/MM at the UB3LYP/BS1:Charmm27 level of theory with QM region B for snapshots $\mathrm{Sn}_{450}$ $\left(\mathrm{Sn}_{500}\right)\left[\mathrm{Sn}_{550}\right]$. Values in curly brackets are the result of a full geometry optimization with basis set BS2. The inset gives an overlay of the optimized geometries of ${ }^{2} \mathrm{TS}_{\mathrm{HAT},-1}$ for the three snapshots with bond lengths in angstroms.

These studies for snapshots $\mathrm{Sn}_{450}, \mathrm{Sn}_{500}$ and $\mathrm{Sn}_{550}$ gave ${ }^{3} \mathrm{TS}_{\mathrm{HAT}, 0, \mathrm{~B}}$ barrier heights of $27.2,26.5$ and $28.1 \mathrm{kcal} \mathrm{mol}^{-1}$ at B3LYP/BSI:Charmm level of theory, whereas with a large basis set of BS2 a barrier height of $27.5 \mathrm{kcal} \mathrm{mol}^{-1}$ was obtained (Supporting Information). As such, the four QM/MM geometry optimizations give an average barrier of $27.3 \pm 0.7 \mathrm{kcal} \mathrm{mol}^{-1}$ and therefore the standard deviation for this set is very small. A comparison of the structure and energetics of the hydrogen atom abstraction from $\mathrm{SubH}_{2}$ by ${ }^{3} \mathrm{O}_{2}$ shows only minor differences upon inclusion of the water molecule in the QM region. Consequently, water molecules in the substrate binding pocket are there to stabilize the structure, but do not appear to have a direct catalytic function.

Pathway (ii): Reaction of $\mathrm{SubH}_{2}$ with ${ }^{2} \mathrm{O}_{2}^{-\bullet}$. Even though the experimental work argued against the availability of a reduction partner, we considered the reaction of $\mathrm{SubH}_{2}$ with superoxide, particularly since the thermochemical analysis from Figure 3 implicated an exergonic reaction for the reaction between dithranol and $\mathrm{O}_{2}{ }^{-\bullet}$. We consequently calculated the mechanism of substrate activation from that reactant complex, i.e. ${ }^{2} \mathrm{Re}^{-}$, with $\mathrm{QM} / \mathrm{MM}$, see Figure 6.
As can be seen from Figure 6, the hydrogen atom abstraction barrier is small with an average value of $2.9 \pm$ $0.2 \mathrm{kcal} \mathrm{mol}^{-1}$ for the four snapshots leading to the radical intermediates in an almost thermoneutral reaction process. Energetically, the hydrogen atom abstraction as calculated with $Q M / M M$, therefore, is similar to what was seen from DFT model complexes (Figure 3) and hence the effect of the protein and the local environment is small. The subsequent $\mathrm{C}-\mathrm{O}$ bond formation step to form the hydroperoxodithranol intermediate ${ }^{2} I_{B,-1}$ is negligible as is the water release to form products. In conclusion, the reaction between superoxo and dithranol is a low energy process that will lead to products efficiently at little energetic costs.

Geometrically (inset of Figure 6), the transition states for the reaction of $\mathrm{O}_{2}^{-\bullet}$ with $\mathrm{SubH}_{2}$ are more central with $\mathrm{C}-\mathrm{H}$ distances of $1.32-1.39 \AA$ and $\mathrm{O}-\mathrm{H}$ distances ranging from $1.23-1.31 \AA$ for the four snapshots. Therefore, structurally and energetically the four transition states are alike. Furthermore, an enlarged basis set has a limited effect and does not seem to alter the structure and energetics dramatically. Accordingly, a superoxo anion can react efficiently with dithranol through oxygen atom transfer with release of a water molecule. 


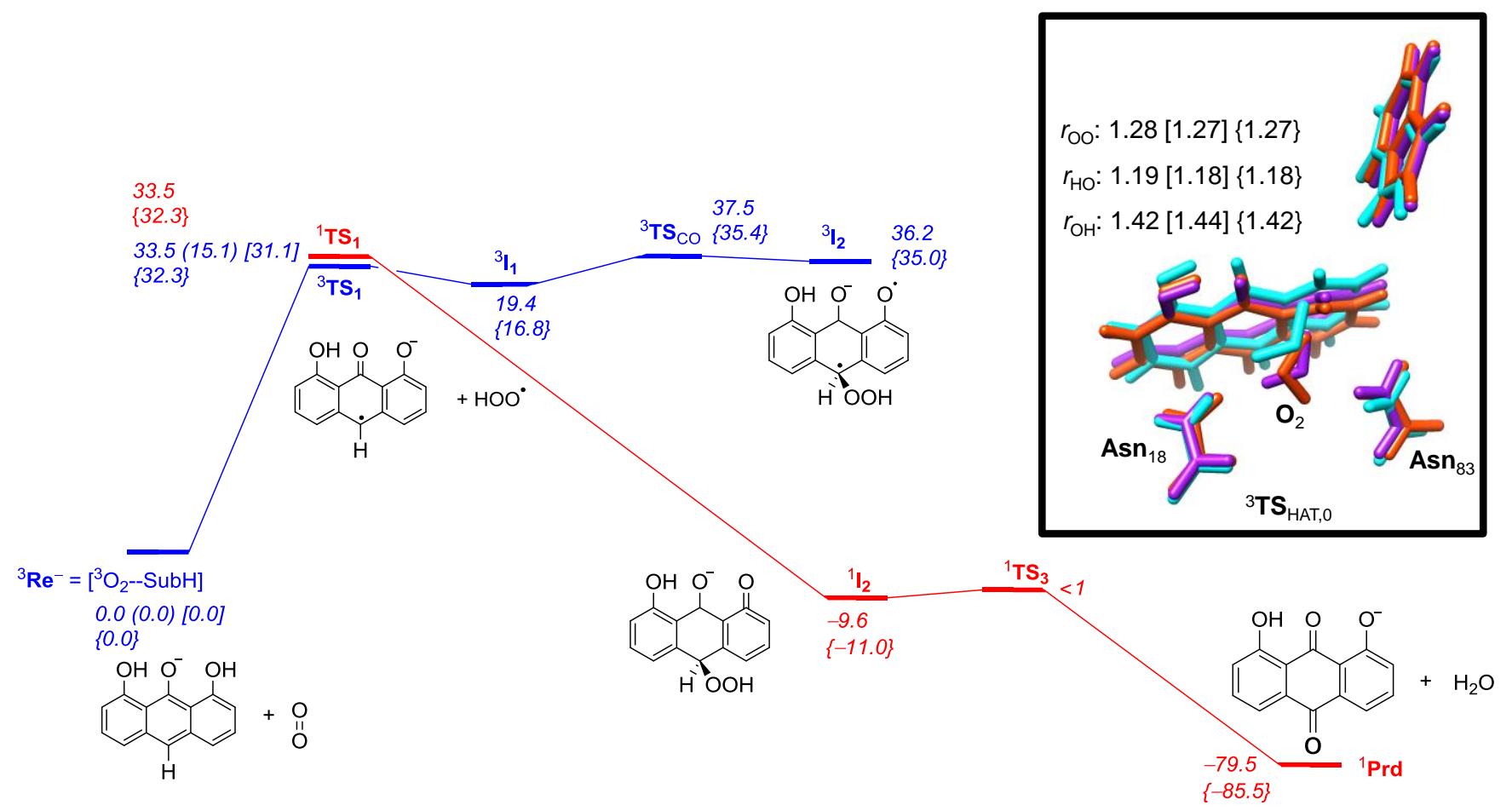

Figure 7: Potential energy landscape (with values in $\mathrm{kcal} \mathrm{mol}^{-1}$ ) for dithranol anion activation by ${ }^{3} \mathrm{O}_{2}$ inside $\mathrm{NMO}$ as calculated with QM/MM. Energies obtained with QM/MM at the UB3LYP/BS1:Charmm27 level of theory with QM region E for snapshots

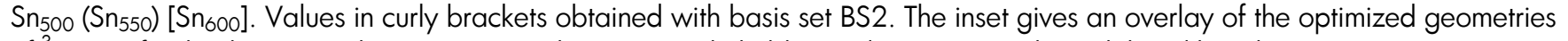
of ${ }^{3} \mathrm{TS}_{\mathrm{HAT}, 0}$ for the three snapshots ( $\mathrm{Sn}_{500}$ in amber, $\mathrm{Sn}_{550}$ in light blue and $\mathrm{Sn}_{600}$ in purple) with bond lengths in angstroms.

Nevertheless, the experimental rate constant of 0.0028 $\mathrm{min}^{-1}$ implicates a slow reaction process, which is inconsistent with a small barrier of about $3 \mathrm{kcal} \mathrm{mol}^{-1}$ as seen in Figure 6. As such, our computational modelling implicates that it is unlikely there is superoxo anion radical available in the active site.

Pathway (iii): Reaction of $\mathrm{SubH}^{-}$with ${ }^{3} \mathrm{O}_{2}$. Finally, we investigated three alternative reaction mechanisms (Scheme 1), whereby dioxygen enters the pocket containing deprotonated dithranol $\left(\mathrm{SubH}^{-}\right)$using $\mathrm{QM} / \mathrm{MM}$ at the UB3LYP/BS1:Charmm27 level of theory. These mechanisms represent possible reaction pathways describing the reaction at neutral and higher $\mathrm{pH}$. Importantly, the reaction of $\mathrm{O}_{2}$ with the $\mathrm{NMO}-\mathrm{SubH}^{-}$complex uniquely leads to the biologically observed desirable monoxygenated species as the major product. ${ }^{33}$

Alongside DFT model complex calculations, we also performed a full QM/MM study on a structure containing deprotonated substrate and ${ }^{3} \mathrm{O}_{2}\left({ }^{3} \mathrm{Re}^{0}-\mathrm{H}^{+}\right)$and the mechanism of substrate activation. A geometry optimization at either the $Q M / M M$ level of theory or on an active site model with DFT gives a $\left[\mathrm{SubH}^{-}-{ }^{3} \mathrm{O}_{2}\right]$ configuration with two unpaired electrons on dioxygen and a negative charge on deprotonated dithranol. Therefore, similarly to the reactant complexes discussed above, no electron transfer takes place upon approach of ${ }^{3} \mathrm{O}_{2}$ on deprotonated substrate.

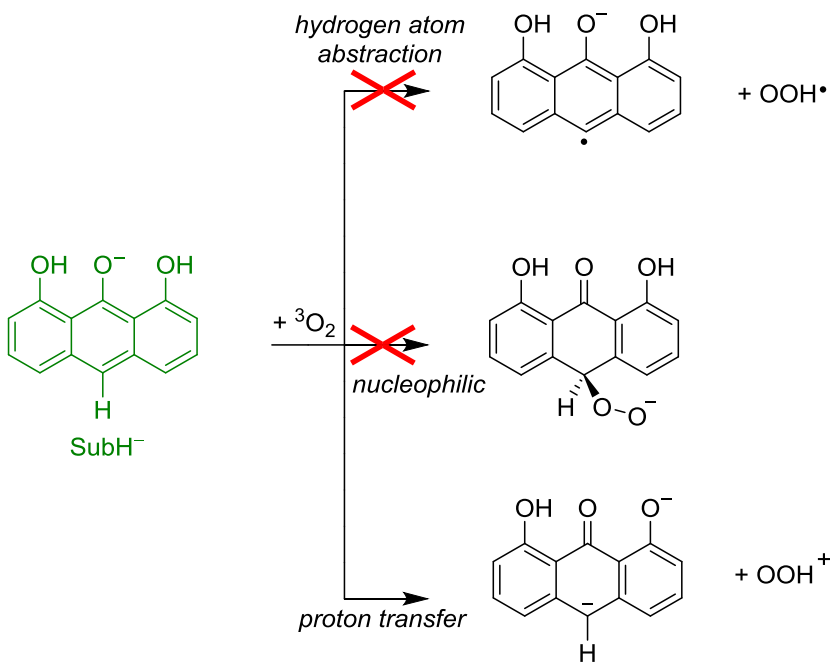

Scheme 1. Reactions tested for deprotonated substrate with dioxygen using $Q M$ region $B$. 
This confirms the results from small model complexes (Figure 3) that predicted an endothermicity for electron transfer of $25.8 \mathrm{kcal} \mathrm{mol}^{-1}$. As such, the model predicts that the protein environment does not stabilize the products sufficiently to make electron transfer feasible. Interestingly, experimental work using superoxide dismutase superoxide scavengers indicated a role for superoxide (or its protonated form) in the formation of the monoxygenase product at alkaline $\mathrm{pH}$ and hence our proposed mechanism may not represent alkaline chemical systems.

Subsequently, three reaction mechanisms were explored starting from this reactant complex $\left({ }^{3} \mathrm{Re}^{0}-\mathrm{H}^{+}\right)$: hydrogen atom abstraction, electrophilic addition of dioxygen to carbon $\mathrm{C}^{12}$ as well as hydrogen atoms abstraction/proton transfer from the phenol group (Scheme 1). Supporting Information Tables S16 and S17 give details of the geometry scans of hydrogen atom abstraction and electrophilic addition. We initially ran constraint geometry scans with $Q M / M M$ using $Q M$ region B to explore the potential energy profile and find information on the likelihood of the mechanism, whereby in stepwise geometry optimizations substrate and oxidant were brought closer together. However, these scans gave continuous increase of the energy upon shortening the distances. Hence, neither the aromatic hydrogen atom abstraction nor the electrophilic addition processes by $\mathrm{SubH}^{-}$is a feasible reaction mechanism.

The final mechanism considered for this model was hydrogen atom abstraction or proton transfer from the phenol group to ${ }^{3} \mathrm{O}_{2}$, Figure 7. The phenol proton is linked in a hydrogen bonding interaction with the indole nitrogen atom of Trp 67 . Therefore, we selected a model where the $Q M$ region included this $\operatorname{Trp}_{67}$ residue, namely $Q M$ region E. Figure 7 displays details of the calculated reaction mechanism and gives optimized geometries of key transition states for proton transfer.

As can be seen from Figure 7, a mechanism is obtained and a transition state for hydrogen atom transfer could be located in all three snapshots. An analysis of the group spin densities, however, shows that these steps correspond to a hydrogen atom abstraction from the phenol group and no proton transfer occurred. Thus, the transition states give spin density distributions of approximately 1 on $\mathrm{O}_{2}$ and 1 on substrate, so that the proton transfer simultaneously has resulted in an electron transfer. Energetically these proton transfer barriers fluctuate dramatically and in snapshots $\mathrm{Sn}_{500}$ and $\mathrm{Sn}_{600}$ they are high in energy with a magnitude of 33.5 and $31.1 \mathrm{kcal} \mathrm{mol}^{-1}$. Therefore, in these snapshots the proton transfer will not be feasible at room temperature. An equivalent energy is found for the optimized geometry of the open shell singlet state. On the other hand, in snapshot $\mathrm{Sn}_{550}$ a low-energy transition state is found of only $15.1 \mathrm{kcal} \mathrm{mol}^{-1}$. It is unclear what the origin of the low energy of the $\mathrm{Sn}_{550}$ proton transfer transition states is. Optimized geometries of the three proton transfer transition states are given in Figure 7 and in general their bond lengths are very similar, although the $\mathrm{O}-\mathrm{O}-\mathrm{C}$ angle and position varies somewhat. As the substrate binding pocket is relative large and open to solvent, many lowenergy conformations should be possible of which we only were able to sample a few.

The subsequent mechanism on the triplet state after hydrogen atom transfer leads to an intermediate ${ }^{3} / 1$ at 16.8 $\mathrm{kcal} \mathrm{mol}^{-1}$ above reactant. Similar to the electronic configuration of the transition state has a spin density of 1 on the $\mathrm{OOH}$ unit and 1 on the organic substrate. Attempts were made to swap molecular orbitals and find the proper proton transfer intermediate as described in Scheme 1; however, it was considerably higher in energy. On the triplet state, thereafter, the reaction proceeds past a second transition state $\mathrm{TS}_{\mathrm{CO}}$ leading to the biradical intermediate ${ }^{3} l_{2}$. The latter is much higher in energy than ${ }^{3} l_{1}$ and may not be accessible. A more likely reaction channel from ${ }^{3} \mathrm{TS}_{1}$; however, is a spin-state crossing to the singlet spin state that relaxes to dithranone products efficiently without high barriers. On the open shell singlet state however, the mechanism after ' ${ }^{2} S_{1}$ directly relaxes to the ${ }^{1} I_{2}$ state. As such a spin-state crossing from triplet to singlet directly leads to ${ }^{1} I_{2}$ after passing ${ }^{3} \mathrm{TS}_{1}$. This may explain the differences in products obtained at low versus high $\mathrm{pH}$ conditions experimentally that reported monoxygenation at high $\mathrm{pH}$ and bisanthrone products at low $\mathrm{pH}^{33}$

Hence, a spin state crossing to the open-shell singlet intermediate gives an exergonic process. A very low barrier $\left(<1 \mathrm{kcal} \mathrm{mol}^{-1}\right)$ will then release a water molecule to form the anionic product. The results obtained with snapshot $\mathrm{Sn}_{500}$ were reproduced well with $\mathrm{Sn}_{600}$ and calculations with a larger basis set also did not lead to major changes. Interestingly, the third snapshot $\left(\mathrm{Sn}_{550}\right)$ gives a proton transfer barrier of only $15.1 \mathrm{kcal} \mathrm{mol}^{-1}$, which would be a thermochemically accessible barrier at room temperature. However, even this barrier is much higher in energy than the one reported for the reaction of superoxo anion radical with substrate (compare the barriers in Figures 6 and 7). Whether these processes will be competitive depends on the energy to form the superoxo anion radical in the protein.

Effect of $\mathrm{Asn}_{18}$ and $\mathrm{Asn}_{63}$ residues. The calculations presented in this work show that two Asn residues $\left(A_{s n_{18}}\right.$ and $A_{s n_{63}}$ ) in the substrate binding pocket can hold and guide molecular oxygen to the $\mathrm{C}^{12}$ position of dithranol for siteselective hydroxylation. To examine their effect in catalysis, we mutated both residues to Ala and reevaluated the reaction mechanism with $\mathrm{QM} / \mathrm{MM}$. 


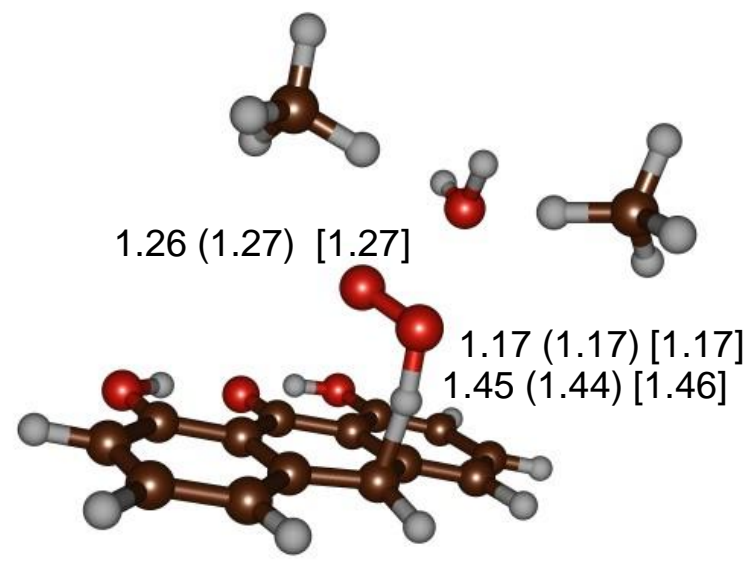

$\Delta \mathrm{E}^{\ddagger}=30.4(29.2)[27.8]$

$\{28.6\}$

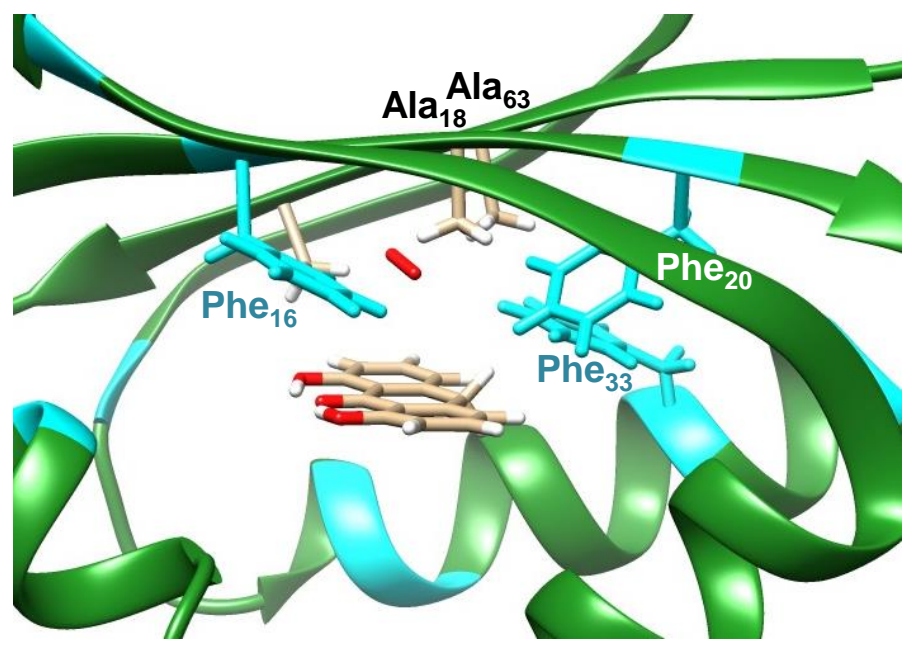

${ }^{3} \mathbf{T S}_{\text {HAT, }, \text { mutants }}$

Figure 8. QM/MM optimized geometries of hydrogen atom abstraction transition states ${ }^{3} \mathrm{TS}_{\mathrm{HAT}, 0, \text { mutants }}$ of the Asn18Ala/Asn63Ala double mutant of $\mathrm{NMO}$ for the reaction of $\mathrm{SubH}_{2}$ with ${ }^{3} \mathrm{O}_{2}$ using QM region C. Data obtained at UB3LYP/BS1:Charmm for $\mathrm{Sn}_{500}$ $\left(\mathrm{Sn}_{550}\right)$ and $\left[\mathrm{Sn}_{600}\right]$ and at UB3LYP/BS1:Charmm27//UB3LYP/BS2:Charmm27 for $\left\{\mathrm{Sn}_{500}\right\}$. Bond lengths are in angstroms and relative energies in $\mathrm{kcal} \mathrm{mol}^{-1}$.

The two Asn groups were replaced by Ala groups manvally and the set-up of the protein structure and particularly the solvation step was redone. In the absence of the Asn groups in the substrate binding pocket, their function is taken over by additional water molecules that are involved in key hydrogen bonding interactions. From the mutant molecular dynamics simulation, we took three snapshots and repeated the full acidic substrate activation mechanism for $\mathrm{SubH}_{2}$ with $\mathrm{O}_{2}$ with $\mathrm{QM} / \mathrm{MM}$.

Optimized geometries of the rate-determining hydrogen atom abstraction transition states ${ }^{3} \mathrm{TS}_{\mathrm{HAT}, 0 \text {, mutants }}$ are given in Figure 8 for three snapshots obtained from MD simulation after 500,550 and 600 ps. As can be seen geometrically and energetically the structures are very similar to each other, but also do not deviate much from the ones given above in Figure 5 for the WT reaction. This is not surprising as in none of the above mentioned calculations significant radical character or charge was found on the Asn side chains. As a result, the hydrogen atom abstraction barrier heights are of similar energy to those found for WT ranging from 27.8 to $30.4 \mathrm{kcal} \mathrm{mol}^{-1}$ for ${ }^{3} \mathrm{TS}_{\mathrm{HAT}, 0, \text { mutants }}$ in the three individual snapshots. Consequently, little energetic and geometric differences are seen for the hydrogen atom abstraction barriers as compared to the studies reported in the previous sections. The hydrogen atom abstraction barriers are late on the potential energy profile with long $\mathrm{C}-\mathrm{H}$ and short $\mathrm{O}-\mathrm{H}$ distances and hence resemble the radical intermediate structures in geometry. As seen before, late

transition states usually correspond with high hydrogen atom abstraction barriers, which indeed is the case for our system. ${ }^{66,67}$ In conclusion, the Asn amino acids in the substrate binding pocket do not appear to have a strong catalytic function. They form hydrogen bonding interactions with dioxygen/superoxo that may guide it into the right direction and set up for attack on position $\mathrm{C}^{12}$ of dithranol. The decrease of the catalytic rates observed experimentally ${ }^{34}$ may be too small to be captured accurately with our computational models. However, the presence of Asn residues appears to influence the electron affinity of the reactant complex and lower it slightly.

\section{Discussion.}

Mechanistic results with respect to experiment. To understand the monoxygenation mechanism of NMO enzymes we analyzed our results in detail and compared the work to flavin, heme and nonheme iron monoxygenases. As shown by the work presented here, several low energy pathways are possible for the activation of dithranol by oxidant at room temperature. In general, our lowest reaction barriers are for a superoxo anion radical $\left(\mathrm{O}_{2}^{--}\right)$in reaction with protonated substrate for which we find activation barriers of approximately $\Delta \mathrm{E}^{\ddagger}=3.0 \mathrm{kcal} \mathrm{mol}^{-1}$ (Figure 6). Experimentally; ${ }^{33}$ however, a second-order rate constant of $k=0.0028 \mathrm{~min}^{-1}$ was measured, which according to transition-state-theory would correspond to a free en- 
ergy of activation of $\Delta G^{\ddagger}=22.2 \mathrm{kcal} \mathrm{mol}^{-1}$ at $298 \mathrm{~K}$. Clearly, the experimental rates cannot correspond to a fast reaction process such as that between $\mathrm{O}_{2}^{-\bullet}$ and $\mathrm{SubH}_{2}$. Consequently, the experimental reaction rates imply that the rate determining step is unlikely to be between superoxo and protonated substrate. The barriers calculated for the reaction of ${ }^{3} \mathrm{O}_{2}$ with $\mathrm{SubH}_{2}$, by contrast, range from $19.5-27.9 \mathrm{kcal} \mathrm{mol}^{-1}$ (Figure 5) depending on snapshot and basis set. As such, these barrier heights compare favorably with the experimental free energy of activation and implicate that the slow reaction rate observed is possibly from a reaction of molecular oxygen with protonated substrate.

The calculations also show barrier height and reaction mechanism changes between the protonated and neutral states of the substrate, which is consistent with the $\mathrm{pH}$ dependence of the rates found experimentally. ${ }^{33}$ In particular, a comparison of the potential energy landscapes given in Figures 5 and 7 show an early triplet-to-singlet spin state crossing under basic conditions leading to dithranone products rapidly. On the other hand, the landscape in Figure 5 proceeds predicts a long-lived radical intermediate ${ }^{3} l_{1}$ where the radical can diffuse out of the substrate binding pocket and form bisanthrone instead. Therefore, the landscape shown in Figure 5 will represent the low pH condition in the protein and should lead to bisanthrone products. By contrast, the landscape displayed in Figure 7 represents the high $\mathrm{pH}$ condition and should lead to monoxygenation of the substrate leading to dithranone. The reactivities discussed in Figure 5 and 7, therefore, are in agreement with the experimentally observed product distributions at low versus high $\mathrm{pH}$ conditions (Scheme 2) that obtained bisanthrone at acidic $\mathrm{pH}^{33}$
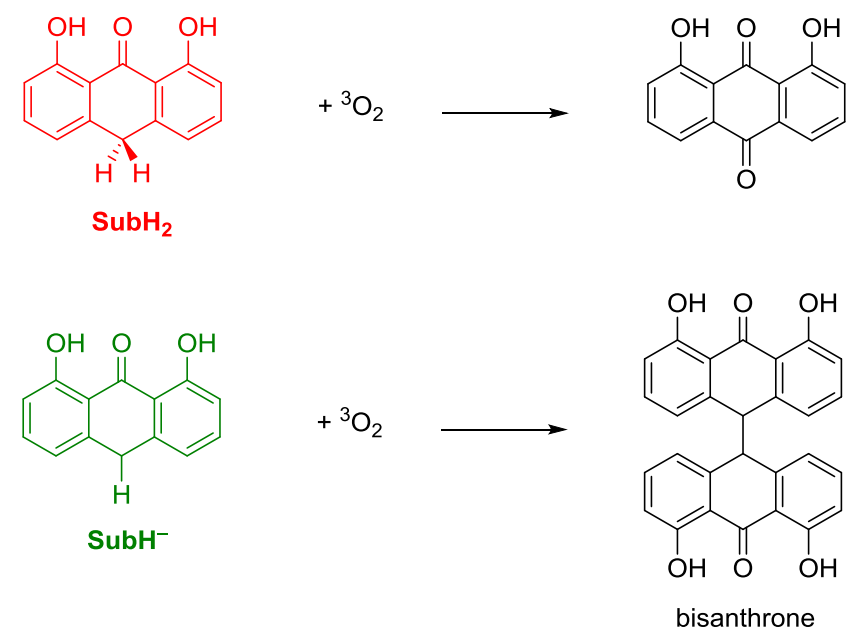

Scheme 2. Products obtained under high $\mathrm{pH}$ (top) and low $\mathrm{pH}$ (bottom) conditions.
Finally, based on radical trap experiments it was suggested that a radical pair is formed, presumably a complex of

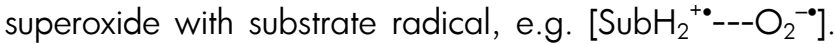
The calculations in both the gas-phase and in an enzyme mimicked environment through $\mathrm{QM} / \mathrm{MM}$ find this state to be high in energy and favor a reactant complex containing ${ }^{3} \mathrm{O}_{2}$. It may very well be that the radical scavengers used in experiment react with an intermediate along the reaction pathway or give a signal due to a side reaction. However, to solve this disparity will require further studies.

Mechanistic pathways of NMO as compared to flavindependent monoxygenases. It has been suggested that antibiotics biosynthesis monoxygenases, although lacking in cofactor, actually might use their substrate as a cofactor instead. ${ }^{32,33}$ As such, the substrate is expected to act similarly to a flavin cofactor in flavin-dependent monoxygenases by reacting with $\mathrm{O}_{2}$ through electron transfer that creates superoxo anion radicals $\left(\mathrm{O}_{2}{ }^{-0}\right)$. Interestingly, our computation work described here contrast work on flavin monoxygenases, whereby a mechanism was proposed starting with electron transfer to form a radical pair complex. $^{68,69}$

To find out why flavin monoxygenases differ from NMO and whether our model gives this different conclusion, we calculated the electron transfer energies in the gas-phase for flavin and dithranol with ${ }^{3} \mathrm{O}_{2}$, see Scheme 3. Thus, the electron transfer from flavin to ${ }^{3} \mathrm{O}_{2}$ is almost thermoneutral and a value of $\Delta G_{\text {reaction }}=2.8 \mathrm{kcal} \mathrm{mol}^{-1}$ is calculated at UB3LYP/6-311++ $G^{* *}$ level of theory with solvent included. The value obtained at the same level of theory for the reaction between dithranol and $\mathrm{O}_{2}$ is $58.3 \mathrm{kcal} \mathrm{mol}^{-1}$ (see also Figure 3). As such, flavin in flavin monoxygenases will react with dioxygen by electron transfer, which is something that dithranol cannot do under the same conditions. Our calculations, therefore, show that flavin-dependent monoxygenases react with molecular oxygen via completely different reaction mechanisms than NMO. This is the result of a much lower ionization energy of flavin as compared to dithranol that enables a fast and efficient electron transfer to molecular oxygen. 

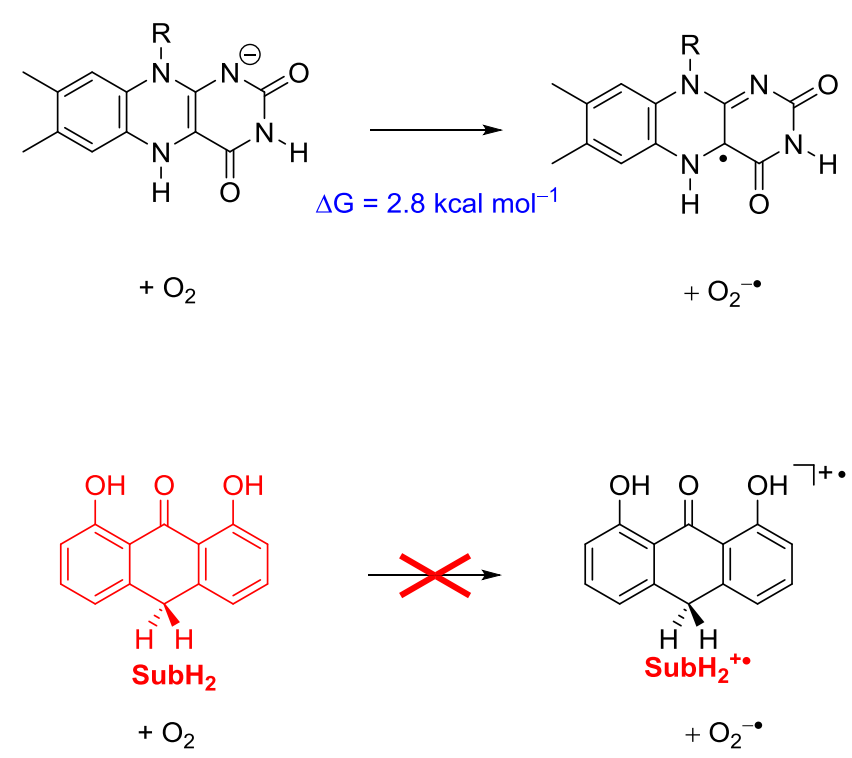

Scheme 3. Electron transfer energies for flavin and dithranol to molecular oxygen.

Mechanistic pathways of NMO as compared to cytochrome P450 monoxygenases. Subsequently, we compare the mechanism and reactivity of the cofactorless dioxygenase NMO with the iron-heme containing cytochrome P450 monoxygenases. ${ }^{7-13}$ Thus, the cytochromes P450 utilize molecular oxygen on a heme-iron active site, whereby the iron(III) resting state has to be reduced to iron(II) to enable $\mathrm{O}_{2}$ binding to form an iron(III)-superoxo intermediate. $^{70-73}$ This species has never been trapped and characterized experimentally, but computational modelling shows it to be a sluggish oxidant in a reaction with substrates. ${ }^{74,75}$ Instead it needs to be reduced and protonated to form the iron(III)-hydroperoxo species. However, the latter is also a sluggish oxidant as found from computational modelling as well as kinetics and spectroscopic studies of biomimetic models for substrate sulfoxidation and epoxidation reactions by the iron(III)hydroperoxo species. ${ }^{76-81}$

In P450 enzymes, therefore, oxygen binding to the heme triggers an electron and proton transfer machinery to generate a high-valent iron(IV)-oxo heme cation radical species (Compound I), which is the active oxidant of the enzyme and reacts with substrates. ${ }^{7-13,70-73,76-81}$ Compound I is a versatile oxidant that reacts with a large range of substrates through oxygen atom transfer (aliphatic and aromatic hydroxylation, sulfoxidation and epoxidation) as well as desaturation and dealkylation reactions. ${ }^{7-19,82,83}$ These enzymes are highly active in the human liver and are involved in biodegradation pathways of, for instance, drug molecules. The versatility of P450 enzymes is thanks to the high activity of the iron(IV)-oxo heme cation radical species (Compound I) that is able to activate relatively strong $\mathrm{C}-\mathrm{H}$ bonds, such as those of propene and cyclohexane. ${ }^{84,85}$ This ability is thanks to the strong $\mathrm{O}-\mathrm{H}$ bond that is formed after hydrogen atom abstraction, ${ }^{86-88}$ as will be discussed in the next section.

Interestingly, recent work on nonheme iron(III)hydroperoxo complexes found it to react efficiently with arenes to form phenol products. ${ }^{89-92}$ This was explained by differences in acidity of heme and nonheme iron(III)hydroperoxo complexes that enable homolytic cleavage of the $\mathrm{O}-\mathrm{O}$ bond by nonheme iron complexes, which is a high energy pathway for heme complexes.

Substrate $\mathrm{C}-\mathrm{H}$ bond strength versus oxidant $\mathrm{O}-\mathrm{H}$ strength . The QM/MM and DFT calculations implicate that although with low rate constants and therefore relatively slow, actually ${ }^{3} \mathrm{O}_{2}$ can abstract a hydrogen atom from neutral dithranol substrate. As there are few substrates ${ }^{3} \mathrm{O}_{2}$ is known to react directly with, we decided to investigate the $\mathrm{C}-\mathrm{H}$ bond strength of dithranol and compare it to typical aliphatic $\mathrm{C}-\mathrm{H}$ bond strengths. To this end we calculated the bond dissociation free energy (BDFE) of the $\mathrm{C}-\mathrm{H}$ bond of a range of aliphatic molecules according to Eq 3 by taking the difference in free energy between the substrate (SubH), a hydrogen atom, and the substrate with one hydrogen atom less (Sub). Previously, it was shown that the BDFE of either the bond that is broken or the bond that is formed correlates with the reaction energy as well as with the activation free energy and consequently the natural logarithm of the rate constant. ${ }^{93-95}$ Further computational modelling on either one oxidant with a range of aliphatic substrates or one substrate with a range of iron(IV)-oxo species confirmed the correlation between free energy of activation and $\mathrm{BDFE}_{\mathrm{CH}} / \mathrm{BDFE}_{\mathrm{OH}} \cdot{ }^{86-88}$

$\mathrm{SubH} \rightarrow \mathrm{Sub}^{\bullet}+\mathrm{H}^{\bullet}+\mathrm{BDFE}_{\mathrm{CH}}$

Table 1 compares DFT calculated $\mathrm{BDFE}_{\mathrm{CH}}$ values of a range of aliphatic substrates. As follows from Table 1, the $\mathrm{C}-\mathrm{H}$ bond strength of dithranol is extremely weak and is of similar strength to that found for the aliphatic $\mathrm{C}-\mathrm{H}$ bonds of 1,3-cyclohexadiene and dihydroanthracene. Therefore, even a weak $\mathrm{C}-\mathrm{H}$ bond oxidant will be able to activate dithranol efficiently. Indeed, molecular oxygen, which is not known to react with many $\mathrm{C}-\mathrm{H}$ bonds directly can activate this bond. The reaction of ${ }^{3} \mathrm{O}_{2}$ with a hydrogen atom calculated using the same methods form ${ }^{\circ} \mathrm{OOH}$ radical with a reaction free energy of $41.4 \mathrm{kcal} \mathrm{mol}^{-1}$, which is the BDFE $_{\mathrm{OH}}$ of the ${ }^{\circ} \mathrm{OOH}$ radical. As shown above in Figure 3, the combination of the $\mathrm{BDFE}_{\mathrm{OH}}$ with the $\mathrm{BDFE}_{\mathrm{CH}}$ of dithranol predicts an endothermic hydrogen atom abstraction of $19.2 \mathrm{kcal} \mathrm{mol}^{-1}$, which compares well with the reac- 
tion energy found between ${ }^{3} \mathrm{Re}^{0}$ and ${ }^{3} \mathrm{I}_{\mathrm{A}, 0}$ reported in Figure 5 .

Table 1. DFT calculated $\mathrm{BDFE}_{\mathrm{CH}}$ values for selected aliphatic substrates.

$\begin{array}{lc}\text { Substrate } & \mathrm{BDFE}_{\mathrm{CH}}{ }^{a} \\ \text { Methane } & 96.2 \\ \text { Ethane } & 90.4 \\ \text { Tolvene (aliphatic) } & 81.5 \\ \text { 9,10-Dihydroanthracene } & 65.2 \\ \text { 1,3-cyclohexadiene } & 62.7 \\ \text { 10-Methyl-9,10-dihydroacridine } & 61.0 \\ \text { Dithranol } & 60.6 \\ { }^{a} \text { in kcal mol }\end{array}$

\section{Conclusions.}

In summary, we present a detailed DFT, QM/MM and thermochemical analysis on the reaction mechanism of substrate activation by NMO enzymes. We considered substrate and dioxygen in several possible electronic and protonation states, namely dithranol in it protonated and deprotonated forms in a reaction with either ${ }^{3} \mathrm{O}_{2}$ or ${ }^{2} \mathrm{O}_{2}{ }^{-*}$. Overall, the computations point to a most likely situation where dioxygen in its triplet spin state reacts with substrate directly. This is possible thanks to the very weak $\mathrm{C}-\mathrm{H}$ bond of the substrate that needs to be broken in the process that even a weak oxidant like ${ }^{3} \mathrm{O}_{2}$ can do. In both protonated and unprotonated states dithranol reacts with ${ }^{3} \mathrm{O}_{2}$ by hydrogen atom transfer; however, the subsequent recombination of oxidant and substrate is energetically difficult with deprotonated substrate. Moreover, the spin state crossing from triplet to singlet happens at a later point in the reaction mechanism as well. Consequently, the calculations predict monoxygenation of dithranol at high $\mathrm{pH}$ (with deprotonated substrate) and radical escape and the formation of bisanthrone products at low $\mathrm{pH}$ (protonated substrate). These computational reaction mechanisms are in good agreement with experimental observation and explain the product distributions.

The alternative mechanisms with superoxo anion radical were also investigated computationally. These pathways give very low hydrogen atom abstraction barriers that implicate a fast and efficient reaction process. Our calculated barriers for the mechanism of dithranol activation by superoxo anion radical are inconsistent with the experimental rate constants and also fail to explain the $\mathrm{pH}$ dependence of the reactions observed. Therefore, the combined DFT and QM/MM calculations rule out the involvement of superoxo anion radical in the reaction mechanism of NMO. In particular, the experimental suggestion that the mechanism of NMO is initiated with electron transfer similar to the flavin monoxygenases cannot be confirmed with the computation. The ionization energy of dithranol is too low for efficient electron transfer as compared to a flavin structure. Our lowest energy pathway is for the reaction of dithranol with superoxo anion radical, it would be interesting to see if the enzyme can be engineered or latched to a reduction partner to generate superoxo efficiently and enable monoxygenase activity with superoxo anions.

\section{ASSOCIATED CONTENT}

Supporting Information. Tables with absolute and relative energies and group spin densities and charges and well as Figures with MD simulations and structures is available as Supporting Information This material is available free of charge via the Internet at http://pubs. acs.org.

\section{AUTHOR INFORMATION}

\section{Corresponding Author}

* sam.devisser@manchester.ac.uk (SPdV); jdubois@chemistry.montana.edu (JD).

\section{Author Contributions}

The manuscript was written through contributions of all authors.

\section{ACKNOWLEDGMENT}

FGCR thanks the Conacyt Mexico for a studentship. JLD thanks the NSF for support (MCB1715176). We thank Prof Robert Szilaghi (University of Montana, USA) for fruitful discussions on possible substrate protonation states and isomeric structures.

\section{ABBREVIATIONS}

P450, cytochrome P450; HOD, 1-H-3-hydroxy-4oxoquinaldine 2,4-dioxygenase; NMO, nogalamycin monoxygenase; DFT, density functional theory; QM/MM, quantum mechanics/molecular mechanics; ET, electron transfer; PT, proton transfer; HAT, hydrogen atom transfer; $\mathrm{HT}$, hydride transfer; pdb, protein databank file.

\section{REFERENCES}

1. Costas, M.; Mehn, M. P.; Jensen, M. P.; Que Jr, L. Dioxygen activation at mononuclear nonheme iron active sites: enzymes, models, and intermediates. Chem. Rev. 2004, 104, 939-986.

2. Abu-Omar, M. M.; Loaiza, A.; Hontzeas, N. Reaction mechanisms of mononuclear non-heme iron oxygenases. Chem. Rev. 2005, 105, 2227-2252.

3. Krebs, C.; Fujimori, D. G.; Walsh, C. T.; Bollinger Jr, J. M. Non-heme Fe(IV)-oxo intermediates. Acc. Chem. Res. 2007, 40, 484-492. 
4. Bruijnincx, P. C. A.; Van Koten, G.; Klein Gebbink, R. J. M. Mononuclear non-heme iron enzymes with the 2-His1-carboxylate facial triad: recent developments in enzymology and modeling studies. Chem. Soc. Rev. 2008, 37, 2716-2744.

5. Solomon, E. I.; Light, K. M.; Liu, L. V.; Srnec, M.; Wong, S. D. Geometric and electronic structure contributions to function in non-heme iron enzymes. Acc. Chem. Res. 2013, 46, 2725-2739

6. Prabhakar, R.; Siegbahn, P. E. M.; Minaev, B. F.; Agren, $\mathrm{H}$. Activation of triplet dioxygen by glucose oxidase: spinorbit coupling in the superoxide lon. J. Phys. Chem. B. 2002, 106, 3742-3750.

7. Sono, M.; Roach, M. P.; Coulter, E. D.; Dawson, J. H. Heme-containing oxygenases Chem. Rev. 1996, 96, 2841-2888.

8. Ortiz De Montellano, P. R., Ed., Cytochrome P450: Structure, Mechanism and Biochemistry, $3^{\text {rd }}$ Ed., Kluwer Academic/Plenum Publishers, New York, 2005.

9. Kadish, K. M.; Smith, K. M.; Guilard, R., Eds., Handbook Of Porphyrin Science, World Scientific Publishing Co., New Jersey, 2010.

10. Grogan, G. Cytochromes P450: exploiting diversity and enabling application as biocatalysts. Curr. Opin. Chem. Biol. 2011, 15, 241-248.

11. Poulos, T. L. Heme enzyme structure and function. Chem. Rev. 2014, 114, 3919-3962.

12. Guengerich, F. P. Common and uncommon cytochrome P450 reactions related to metabolism and chemical toxicity. Chem. Res. Toxicol. 2001, 14, 611-650.

13. Huang, X.; Groves, J. T. Beyond ferryl-mediated hydroxylation: 40 years of the rebound mechanism and $\mathrm{C}-\mathrm{H}$ activation. J. Biol. Inorg. Chem. 2017, 22, 185-207.

14. Meunier, B.; de Visser, S. P.; Shaik, S. Mechanism of oxidation reactions catalyzed by cytochrome P450 enzymes. Chem. Rev. 2004, 104, 3947-3980.

15. Denisov, I. G.; Makris, T. M.; Sligar, S. G.; Schlichting, I. Structure and chemistry of cytochrome P450. Chem. Rev. 2005, 105, 2253-2277.

16. Ortiz De Montellano, P. R. Hydrocarbon hydroxylation by cytochrome P450 enzymes. Chem. Rev. 2010, 110, 932948.

17. Li, D.; Wang, Y.; Han, K. Recent density functional theory model calculations of drug metabolism by cytochrome P450. Coord. Chem. Rev. 2012, 256, 1137-1150.

18. Blomberg, M. R. A.; Borowski, T.; Himo, F.; Liao, R.-Z.; Siegbahn, P. E. M. Quantum chemical studies of mechanisms for metalloenzymes. Chem. Rev. 2014, 114, 36013658.

19. de Visser, S. P.; Kumar, D., Eds., Iron-Containing Enzymes: Versatile Catalysts of Hydroxylation Reaction in Nature, RSC Publishing, Cambridge (UK), 2011.

20. Baver, I.; Max, N.; Fetzner, S.; Lingens, F. 2,4Dioxygenases catalyzing $\mathrm{N}$-heterocyclic-ring cleavage and formation of carbon monoxide. Eur. J. Biochem. 1996, 240, 576-583.

21. Steiner, R. A.; Janssen, H. J.; Roversi, P.; Oakley, A. J.; Fetzner, S. Structural basis for cofactor-independent dioxygenation of $\mathrm{N}$-heteroaromatic compounds at the al- pha/beta-hydrolase fold. Proc. Natl. Acad. Sci. USA 2010, 107, 657-662.

22. Fetzner, S.; Steiner, R. A. Cofactor-independent oxidases and oxygenases. Appl. Microbiol. Biotechnol. 2010, 86, 791-804.

23. Thierbach, S.; Bui, N.; Zapp, J.; Chhabra, S. R.; Kappl, R.; Fetzner, S. Substrate-assisted $\mathrm{O}_{2}$ activation in a cofactor-independent dioxygenase. Chem. Biol. 2014, 20, 19.

24. Hernández-Ortega, A.; Quesne, M. G.; Bui, S.; Heuts, D. P. H. M.; Steiner, R. A.; Heyes, D. J.; de Visser, S. P.; Scrutton, N. S. Origin of the proton-transfer step in the cofactor-free (1H)-3-hydroxy-4-oxoquinaldine 2,4dioxygenase: effect of the basicity of an active site His residue. J. Biol. Chem. 2014, 289, 8620-8632.

25. Hernández-Ortega, A.; Quesne, M. G.; Bui, S.; Heyes, D. J.; Steiner, R. A.; Scrutton, N. S.; de Visser, S. P. Catalytic mechanism of cofactor-free dioxygenases and how they circumvent spin-forbidden oxygenation of their substrates. J. Am. Chem. Soc. 2015, 137, 7474-7487.

26. Silva, $\mathrm{P}$. J. Refining the reaction mechanism of $\mathrm{O}_{2}$ towards its co-substrate in cofactor-free dioxygenases. Peer J. 2016, DOI: 10.7717/Peerj.2805.

27. Sciara, G.; Kendrew, S. G.; Miele, A. E.; Marsh, N. G.; Federici, L.; Malatesta, F.; Schimperna, G.; Savino, C.; Vallone, B. The structure of actva-Orf6, a novel type of monooxygenase involved in actinorhodin biosynthesis. $E M B O$ J. 2003, 22, 205-215.

28. Taguchi, T.; Yabe, M.; Odaki, H.; Shinozaki, M.; MetsaKetela, M.; Arai, T.; Okamoto, S.; Ichinose, K. Biosynthetic conclusions from the functional dissection of oxygenases for biosynthesis of actinorhodin and related Streptomyces antibiotics Chem. Biol. 2013, 20, 510-520.

29. Kendrew, S. G.; Hopwood, D. A.; Marsh, E. N. G. Identification of a monooxygenase from Streptomyces coelicolor A3(2) involved in biosynthesis of actinorhodin: purification and characterization of the recombinant enzyme. J. Bacteriol. 1997, 179, 4305-4310.

30. Rafanan, E. R.; Le, L.; Zhao, L. L.; Decker, H.; Shen, B. Cloning, sequencing, and heterologous expression of the elmghij genes involved in the biosynthesis of the polyketide antibiotic elloramycin from Streptomyces Olivaceus Tü235. J. Nat. Prod. 2001, 64, 444-449.

31. Ye, J. S.; Dickens, M. L.; Plater, R.; Li, Y.; Lawrence, J.; Strohl, W. R. Isolation and sequence analysis of polyketide synthase genes from the daunomycin-producing Streptomyces Sp. strain C5. J. Bacteriol. 1994, 176, 6270-6280.

32. Siitonen, V.; Blauenburg, B.; Kallio, P.; Mäntsälä, P.; Metsä-Ketelä, M. Discovery of a two-component monooxygenase Snoaw/Snoal2 Involved in nogalamycin biosynthesis. Chem. Biol. 2012, 19, 638-646.

33. Machovina, M. M.; Usselman, R. J.; Dubois, J. L. Monooxygenase substrates mimic flavin to catalyze cofactorless oxygenations. J. Biol. Chem. 2016, 291, 1781617828.

34. Grocholski, T.; Koskiniemi, H.; Lindqvist, Y.; Mantsala, P.; Niemi, J.; Schneider, G. Crystal structure of the cofactorindependent monooxygenase Snoab from Streptomyces 
Nogalater. implications for the reaction mechanism. Biochemistry 2010, 49, 934-944.

35. Kralj, M.; Uzelac, L.; Wang, Y.-H.; Wan, P.; Tireli, M.; Mlinarić-Majerski, K.; Piantanida, I.; Basarić, N. Enhancement of antiproliferative activity by phototautomerization of anthrylphenols. Photochem. Photobiol. Sci. 2015, 14, 1082-1092.

36. Muller, K.; Wiegrebe, W.; Younes, M. Formation of active oxygen species by dithranol, III dithranol, active oxygen species and lipid peroxidation in vivo. Arch. Pharm. 1987, 320, 59-66.

37. Müller, K. Antipsoriatic and proinflammatory action of anthralin: implications for the role of oxygen radicals. Biochem. Pharmacol. 1997, 53, 1215-1221.

38. Faponle, A. S.; Quesne, M. G.; de Visser, S. P. Origin of the regioselective fatty acid hydroxilation versus decarboxylation by a cytochrome P450 peroxygenase: what drives the reaction to biofuel production? Chem. Eur. J. 2016, 22, 5478-5483.

39. Quesne, M. G.; Borowski, T.; de Visser, S. P. Quantum mechanics/molecular mechanics modelling of enzymatic processes: caveats and breakthroughs. Chem. Eur. J. 2016, 22, 2562-2581.

40. Hofer, T. S.; de Visser, S. P. Quantum mechani$\mathrm{cal} /$ molecular mechanical approaches for the investigation of chemical systems - recent developments and advanced applications. Front. Chem. 2018, 6, article 357, doi: 10.3389/fchem.2018.00357

41. Frisch, M. J.; Trucks, G. W.; Schlegel, H. B.; Scuseria, G. E.; Robb, M. A.; Cheeseman, J. R.; Scalmani, G.; Barone, V.; Mennucci, B.; Petersson, G. A.; et al. Gaussian, Inc., Wallingford CT, 2013.

42. Becke, A. D. Density-functional thermochemistry. III. the role of exact exchange. J. Chem. Phys. 1993, 98, 56485652.

43. Lee, C.; Yang, W.; Parr, R. G. Development of the ColleSalvetti correlation-energy formula into a functional of the electron density. Phys. Rev. B1988, 37, 785-789.

44. Ditchfield, R.; Hehre, W. J.; Pople, J. A. Self- Consistent molecular-orbital methods. IX. An extended Gaussiantype basis for molecular- orbital studies of organic molecules. J. Chem. Phys. 1971, 54, 724-728.

45. Zoete, V.; Cuendet, M. A.; Grosdidier, A.; Michielin, O. Swiss Param, A Fast Force Field Generation Tool for Small Organic Molecules. J. Comput. Chem. 2011, 32, 23592368.

46. Grossdidier, A.; Zoete, V.; Michielin, O. Swissdock, A Protein-Small Molecule Docking Web Service Basedvon Eadocks DSS. Nucleic Acids Res. 2011, (web server issue) PMID: 21624888, DOI: 10.1093/Nar/Gkr366.

47. Grosdidier, A. Zoete, V. Michielin, O. Fast docking using the CHARMM force field with EADock DSS. J. Comput. Chem. 2011, 32, 2149-2159.

48. Quesne, M. G.; Latifi, R.; Gonzalez-Ovalle, L. E.; Kumar, D.; de Visser, S. P. Quantum mechanics/molecular mechanics study on the oxygen binding and substrate hydroxylation step in AlkB repair enzymes. Chem. Eur. J. 2014, 20, 435-446.

49. Faponle, A. S.; Seebeck, F. P.; de Visser, S. P. Sulfoxide synthase versus cysteine dioxygenase reactivity in a non- heme iron enzyme. J. Am. Chem. Soc. 2017, 139, 92599270.

50. Timmins, A.; Saint-André, M.; de Visser, S. P. Understanding how prolyl-4-hydroxylase structure steers a ferryl oxidant toward scission of a strong C-H bond. J. Am. Chem. Soc. 2017, 139, 9855-9866.

51. Timmins, A.; de Visser, S. P. How are substrate binding and catalysis affected by mutating Glu127 and Argl61 in prolyl-4-hydroxylase? A QM/MM and MD study. Frontiers Chem. 2017, 5, Article 94.

52. Schöneboom, J. C.; Cohen, S.; Lin, H.; Shaik, S.; Thiel, W. Quantum Mechanical/Molecular Mechanical Investigation of the Mechanism of C-H Hydroxylation of Camphor by Cytochrome P450cam: Theory Supports a TwoState Rebound Mechanism. J. Am. Chem. Soc. 2004, 126, 4017-4034.

53. Kumar, D.; Thiel, W.; de Visser, S. P. Theoretical Study on the Mechanism of the Oxygen Activation Process in Cysteine Dioxygenase Enzymes. J. Am. Chem. Soc. 2011, 133, 3869-3882.

54. Dolinsky, T. J.; Czodrowski, P.; Li, H.; Nielsen, J. E.; Jensen, J. H.; Klebe, G.; Baker, N. A. PDB2PQR: expanding and upgrading automated preparation of biomolecular structures for molecular simulations. Nucl. Acids Res. 2007, 35, 522-525.

55. Brooks, B. R.; Bruccoleri, R. E.; Olafson, B. D.; States, D. J.; Swaminathan, S.; Karplus, M. CHARMM: A program for macromolecular energy, minimization, and dynamics calculations. J. Comput. Chem. 1983, 4, 187-217.

56. Dalmas, O.; Cuello, L. G.; Jogini, V.; Cortes, D. M.; Roux, B.; Perozo, E. Structural dynamics of the magnesiumbound conformation of CorA in a lipid bilayer. Structure 2010, 18, 868-878.

57. Bakowies, D.; Thiel, W. Hybrid models for combined quantum mechanical and molecular mechanical approaches. J. Phys. Chem. 1996, 100, 10580-10594.

58. Hratchian, H. P.; Parandekar, P. V.; Raghavachari, K.; Frisch, M. J.; Vreven, T. QM:QM electronic embedding using Mulliken atomic charges: energies and analytic gradients in an ONIOM framework. J. Chem. Phys. 2008, 128, 034107

59. Hitzenberger, M.; Hofer, T. S. Probing the range of applicability of structure and energy-adjusted $Q M / M M$ link bonds. J. Comput. Chem. 2015, 36, 1929-1939.

60. Ahlrichs, R.; Bär, M.; Häser, M.; Horn, H.; Kölmel, C. Electronic structure calculations on workstation computers: the program system turbomole. Chem. Phys. Lett. 1989, 162, 165-169.

61. Smith, W.; Forester, T. R. DL_POLY_2.0: A generalpurpose parallel molecular dynamics simulation package. J. Mol. Graphics 1996, 14, 136-141.

62. Todorov, I. T.; Smith, W.; Trachenko, K.; Dove, M. T. DL_POLY_3: new dimensions in molecular dynamics simulations via massive parallelism. J. Mater. Chem. 2006, 16, 1911-1918.

63. Sherwood, P.; De Vries, A. H.; Guest, M. F.; Schreckenbach, G.; Catlow, C. R. A.; French, S. A.; Sokol, A. A.; Bromley, S. T.; Thiel, W.; Turner, A. J.; et al. QUASI: a general purpose implementation of the $Q M / M M$ ap- 
proach and its application to problems in catalysis. J. Mol. Struct. 2003, 632, 1-28.

64. Schafer, A.; Horn, H.; Ahlrichs, R. Fully optimized contracted Gaussian basis sets for atoms Li to Kr. J. Chem. Phys. 1992, 97, 2571-2577.

65. Berraud-Pache, R.; Lindh, R.; Navizet, I. QM/MM study of the formation of the dioxetanone ring in fireflies through a superoxide lon. J. Phys. Chem. B 2018, 122, 51735182.

66. Kumar, D.; Karamzadeh, B.; Sastry, G. N.; de Visser, S. $P$. What factors influence the rate constant of substrate epoxidation by compound I of cytochrome P450 and analogous iron(IV)-oxo oxidants? J. Am. Chem. Soc. 2010, 132, 7656-7667.

67. Kumar, D.; Latifi, R.; Kumar, S.; Rybak-Akimova, E. V.; Sainna, M. A.; de Visser, S. P. Rationalization of the barrier height for $p$-Z-styrene epoxidation by iron(IV)-oxo porphyrin cation radicals with variable axial ligands. Inorg. Chem. 2013, 52, 7968-7979.

68. Chaiyen, P.; Fraaije, M. W.; Mattevi, A. The enigmatic reaction of flavins with oxygen. Trends Biochem. Sc. 2012, 37, 373-380.

69. Visitsatthawong, S.; Chenprakhon, P.; Chaiyen, P.; Surawatanawong, $P$. Mechanism of oxygen activation in a flavin-dependent monooxygenase: a nearly barrierless formation of $\mathrm{C} 4 \mathrm{a}$-hydroperoxy flavin via proton-coupled electron transfer. J. Am. Chem. Soc. 2015, 137, 93639374.

70. de Visser, S. P.; Shaik, S.; Sharma, P. K.; Kumar, D.; Thiel, W. Active species of horseradish peroxidase (HRP) and cytochrome P450: two electronic chameleons. J. Am. Chem. Soc. 2003, 125, 15779-15788.

71. Li, X.-X.; Postils, V.; Sun, W.; Faponle, A. S.; Solà, M.; Wang, Y.; Nam, W.; de Visser, S. P. Reactivity patterns of (protonated) compound II and compound I of cytochrome P450: which is the better oxidant? Chem. Eur. J. 2017, 23, 6406-6418.

72. Shaik, S.; Kumar, D.; de Visser, S. P.; Altun, A.; Thiel, W. Theoretical perspective on the structure and mechanism of cytochrome P450 enzymes. Chem. Rev. 2005, 105, 2279-2328.

73. de Visser, S. P.; Nam, W. High-valent iron-oxo porphyrins in oxygenation reactions. In Handbook of Porphyrin Science, Kadish, K. M.; Smith, K. M.; Guilard, R. (Eds.); World Scientific Publishing Co., New Jersey, 2010, Chapter 44, pp. 85-140.

74. Latifi, R.; Tahsini, L.; Nam, W.; de Visser, S. P. Regioselectivity of aliphatic versus aromatic hydroxylation by a nonheme iron(II)-superoxo complex. Phys. Chem. Chem. Phys. 2012, 14, 2518-2524.

75. Jastrzebski, R.; Quesne, M. G.; Weckhuysen, B. M.; de Visser, S. P.; Bruijnincx, P. C. A. Experimental and computational evidence for the mechanism of intradiol catechol dioxygenation by non-heme iron(III) complexes. Chem. Eur. J. 2014, 20, 15686-15691.

76. Ogliaro, F.; de Visser, S. P.; Cohen, S.; Sharma, P. K.; Shaik, S. Searching for the second oxidant in the catalytic cycle of cytochrome P450: a theoretical investigation of the iron(III)-hydroperoxo species and its epoxidation pathways. J. Am. Chem. Soc. 2002, 124, 2806-2817.
77. Sharma, P. K.; de Visser, S. P.; Shaik, S. Can a single oxidant with two spin states masquerade as two different oxidants? a study of the sulfoxidation mechanism by cytochrome P450. J. Am. Chem. Soc. 2003, 125, 86988699.

78. Porro, C. S.; Sutcliffe, M. J.; de Visser, S. P. Quantum mechanics/molecular mechanics studies on the sulfoxidation of dimethyl sulfide by compound I and compound 0 of cytochrome P450: which is the better oxidant? J. Phys. Chem. A 2009, 113, 11635-11642.

79. Park, M. J.; Lee, J.; Suh, Y.; Kim, J.; Nam, W. Reactivities of mononuclear non-heme iron intermediates including evidence that iron(III)-hydroperoxo species is a sluggish oxidant. J. Am. Chem. Soc. 2006, 128, 2630-2634.

80. Franke, A.; Wolak, M.; Van Eldik, R. Factors that affect the nature of the final oxidation products in "peroxoshunt" reactions of iron-porphyrin complexes. Chem. Eur. J. 2009, 15, 10182-10198.

81. Fertinger, C.; Hessenauer-llicheva, N.; Franke, A.; Van Eldik, R. Direct comparison of the reactivity of model complexes for compounds $\mathrm{O}$, I, and II in oxygenation, hydrogen-abstraction, and hydride-transfer processes. Chem. Eur J. 2009, 15, 13435-13440.

82. Kumar, D.; Sastry, G. N.; de Visser, S. P. Axial ligand effect on the rate constant of aromatic hydroxylation by iron(IV)-oxo complexes mimicking cytochrome P450 enzymes. J. Phys. Chem. B2012, 116, 718-730.

83. Sainna, M. A.; Kumar, S.; Kumar, D.; Fornarini, S.; Crestoni, M. E.; de Visser, S. P. A comprehensive test set of epoxidation rate constants by iron(IV)-oxo porphyrin complexes. Chem. Sci. 2015, 6, 1516-1529.

84. Groves, J. T.; Nemo, T. E. Aliphatic hydroxylation catalyzed by iron porphyrin complexes. J. Am. Chem. Soc. 1983, 105, 6243-6248.

85. Groves, J. T.; Avaria-Neisser, G. E.; Fish, K. M.; Imachi, M.; Kuczkowski, R. L. Hydrogen-deuterium exchange during propylene epoxidation by cytochrome P-450. J. Am. Chem. Soc. 1986, 108, 3837-3838.

86. Shaik, S.; Kumar, D.; de Visser, S. P. A Valence bond modelling of trends in hydrogen abstraction barriers and transition states of hydroxylation reactions catalyzed by cytochrome P450 enzymes. J. Am. Chem. Soc. 2008, 130, 10128-10140.

87. Latifi, R.; Bagherzadeh, M.; de Visser, S. P. Origin of the correlation of the rate constant of substrate hydroxylation by nonheme iron(IV)-oxo complexes with the bonddissociation energy of the $\mathrm{C}-\mathrm{H}$ bond of the substrate. Chem. Eur. J. 2009, 15, 6651-6662.

88. de Visser, S. P. Trends in substrate hydroxylation reactions by heme and nonheme iron(IV)-oxo oxidants give correlations between intrinsic properties of the oxidant with barrier. J. Am. Chem. Soc. 2010, 132, 1087-1097.

89. Vardhaman, A. K.; Sastri, C. V.; Kumar, D.; de Visser, S. P. Nonheme ferric hydroperoxo intermediates are efficient oxidants of bromide oxidation. Chem. Commun. 2011, 47, 11044-11046

90. Thibon, A.; Jollet, V.; Ribal, C.; Sénéchal-David, K.; BilIon, L.; Sorokin, A. B.; Banse, F. Hydroxylation of aromatics with the help of a non-haem $\mathrm{FeOOH}$ : a mechanistic 
study under single-turnover and catalytic conditions. Chem. Eur. J. 2012, 18, 2715-2724.

91. Faponle, A. S.; Quesne, M. G.; Sastri, C. V.; Banse, F.; de Visser, S. P. Differences and comparisons of the properties and reactivities of iron(III)-hydroperoxo complexes with saturated coordination sphere. Chem. Eur. J. 2015, 21, 1221-1236.

92. Faponle, A. S.; Banse, F.; de Visser, S. P. Arene activation by a nonheme iron(III)-hydroperoxo complex: pathways leading to phenol and ketone products. J. Biol. Inorg. Chem. 2016, 21, 453-462.
93. Friedrich, L. E. The two hydrogen-oxygen bonddissociation energies of hydroquinone. J. Org. Chem. 1983, 48, 3851-3852.

94. Bordwell, F. G.; Cheng, J.-P. Substituent effects on the stabilities of phenoxyl radicals and the acidities of phenoxyl radical cations. J. Am. Chem. Soc. 1991, 113, 17361743.

95. Mayer, J. M. Hydrogen atom abstraction by metal-oxo complexes: understanding the analogy with organic radical reactions. Acc. Chem. Res. 1998, 31, 441-450. 
TOC Graphic:

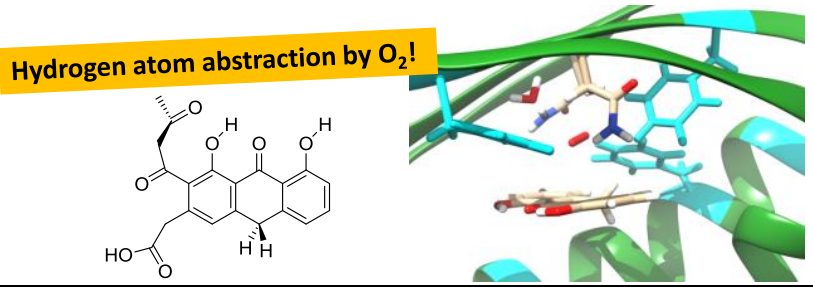

